\title{
Essay
}

\section{To Insure Prejudice: Racial Disparities in Taxicab Tipping}

\author{
Ian Ayres, ${ }^{\dagger}$ Fredrick E. Vars, ${ }^{\dagger \dagger}$ and Nasser Zakariya ${ }^{\dagger \dagger \dagger}$
}

\section{CONTENTS}

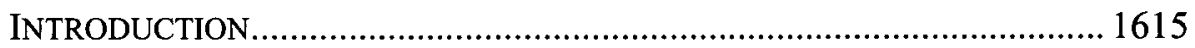

I. RACE AND THE HISTORY OF TIPPING ......................................... 1619

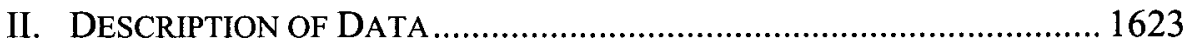

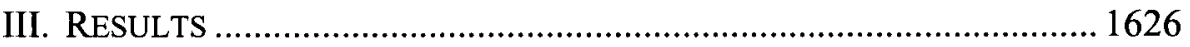

A. Lower Tips for Minority Drivers........................................... 1627

B. Lower Tips by Minority Passengers ........................................ 1628

C. Driver and Passenger Racial Intersections .............................. 1629

$\dagger$ William K. Townsend Professor of Law, Yale Law School. Please send comments to ian.ayres@yale.edu. This Essay is dedicated to Underhill Moore and Suzanne Perry. Moore took to the streets of New Haven during the 1930s to see whether people observed traffic and parking meter regulations. Underhill Moore \& Charles C. Callahan, Law and Learning Theory: A Study in Legal Control, 53 YALE L.J. 1 (1943). Nearly seventy years later, Perry conducted a pilot study of taxi and pizza delivery tipping that was the inspiration and foundation for the present effort. The authors thank Aditi Bagchi, Caroline Harada, Lee Harris, and Ian Slotin for their heroic efforts as auditors. Orley Ashenfelter, Jennifer Brown, Marcus Cole, Emma Coleman, John Donohue, Ted Eisenberg, Daniel Ho, Christine Jolls, Neal Katyal, Steve Levitt, Michael Lynn, and seminar participants at Georgetown, Princeton, the University of New South Wales, the University of North Carolina at Chapel Hill, and Yale provided helpful comments. The data and statistical analysis (in Stata format) for this Essay are available at intp://www.yalelawjournal.org.

†† Associate, Miller Shakman \& Hamilton LLP.

$\dagger \dagger \dagger$ Ph.D. candidate, Department of the History of Science, Harvard University. 
D. Regression Analysis

IV. TESTS OF DRIVER “STATISTICAL DISCRIMINATION” INFERENCES..... 1632

A. Evidence of Driver Discrimination ........................................ 1632

B. Tests of Statistical Discrimination .............................................. 1634

V. ALTERNATIVE (NONRACIAL) HYPOTHESES ................................... 1642

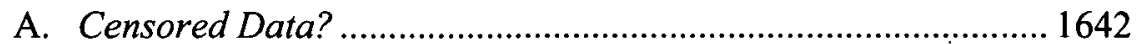

B. Lower Tips for Minority Drivers............................................. 1644

C. Lower Tips by Minority Passengers ........................................ 1648

VI. WHY ARE CONSUMERS DISCRIMINATING? .................................... 1653

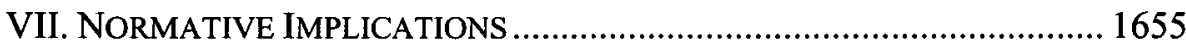

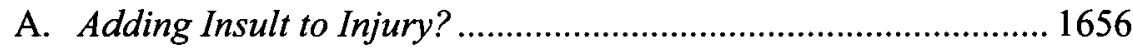

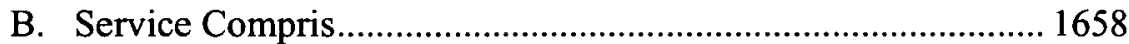

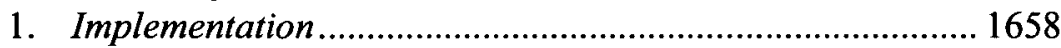

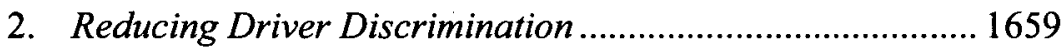

3. Countervailing Effects .................................................. 1661

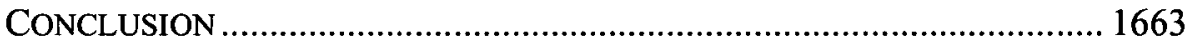

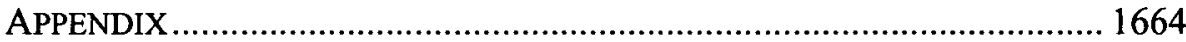




\section{INTRODUCTION}

It has become increasingly common to test whether sellers in retail markets discriminate against buyers. ${ }^{1}$ But this Essay is one of the first efforts to test the other side of the market. ${ }^{2}$ It examines whether retail consumers discriminate against sellers on the basis of the sellers' race. Even though Gary Becker long ago understood that consumers' "taste[] for discrimination" could cause sellers to discriminate against other customers $^{3}$-for example, leading restaurant owners to maintain racially segregated lunch counters - almost no one has tested whether consumers' taste for discrimination might be directed at a seller's race itself (or the race of a seller's employees).

This failure to test is unjustified. Tests of consumer-side race discrimination are just as feasible as seller-side testing. Consumer price discrimination might be observed in car and house negotiations and auction markets (including online markets such as eBay). Of course, the ability of consumers to discriminate in terms of pricing is often severely constrained. Outside of auction and negotiated-pricing regimes, consumers are generally presented with a fixed price.

But in virtually any market, there is the possibility that consumer willingness to contract is influenced by the race of the seller or the race of

1. See, e.g., IAN AYReS, PeRVASIVE PreJUdice?: UnConVENTIONAL EVIDENCE of RACE AND GENDER DisCRIMINATION (2001); Peter Siegelman, Race Discrimination in "Everyday" Commercial Transactions: What Do We Know, What Do We Need To Know, and How Can We Find Out, in A NATIONAL REPORT CARD ON DISCRIMINATION IN AMERICA: ThE ROLE OF TESTING 69 (Michael Fix \& Margery Austin Turner eds., 1999); see also John Yinger, Evidence on Discrimination in Consumer Markets, J. ECON. PERSP., Spring 1998, at 23.

2. The only other direct test of consumer race discrimination that we were able to find was a study of buyer behavior at baseball card trading shows when the seller's race was manipulated. John A. List, The Nature and Extent of Discrimination in the Marketplace: Evidence from the Field, 119 Q.J. ECON. 49, 56 (2004). Some studies have indirectly inferred the presence of consumer discrimination. See, e.g., Lawrence M. Kahn \& Peter D. Sherer, Racial Differences in Professional Basketball Players'. Compensation, 6 J. LAB. ECON. 40, 42 (1988) ("[A]ll else equal, white representation on a team contributes to home attendance, providing evidence consistent with the idea of consumer discrimination."); Clark Nardinelli \& Curtis Simon, Customer Racial Discrimination in the Market for Memorabilia: The Case of Baseball, 105 Q.J. ECON. 575, 576 (1990) ("The appeal of sports for studies of discrimination is that it is possible to separate consumer discrimination from ability to do the work."). Employment audits are nonretail tests of whether consumers of labor (i.e., employers) discriminate on the basis of seller race. Keith R. Ihlanfeldt \& Madelyn V. Young, Intrametropolitan Variation in Wage Rates: The Case of Atlanta Fast-Food Restaurant Workers, 76 REV. ECON. \& STAT. 425, 425 (1994) ("[E]vidence on discrimination suggests that consumer discrimination affects the wages paid to black workers."); see also John Yinger, Measuring Racial Discrimination with Fair Housing Audits: Caught in the Act, 76 AM. ECON. REV. 881, 881 (1986) ("Housing agents cater to the racial prejudice of current or potential white customers.").

3. GARY S. BECKER, THE ECONOMICS OF DISCRIMINATION 57, 57-62 (1957). 
the seller's employees. ${ }^{4}$ Audit procedures could easily be designed to test for disparate treatment by buyers with regard to refusals to deal. For example, prospective buyers at a real estate office could be randomly assigned to a white or minority sales agent and then tested to see whether a white agent is more likely to make a sale then a minority agent using the same sales pitch.

In this study, we have tested for consumer discrimination in taxicab tipping, because it is a dimension of consumer economic behavior that is both discretionary and potentially observable. In addition to illuminating this important area of economic behavior, we hope this study of tipping behavior will convince other researchers to test for consumer discrimination in other contexts-particularly regarding willingness to contract. The failure of civil rights advocates to undertake such studies leaves one side of every market interaction inappropriately unexamined and unregulated.

We collected data on more than 1000 tips to taxicab drivers in New Haven, Connecticut in 2001. After controlling for a host of other variables, we find two potential racial effects: (1) African-American cab drivers on average were tipped approximately one-third less than white cab drivers, and (2) African-American and Hispanic passengers tipped approximately one-half the amount of white passengers.

African-American passengers also seemed to participate in the racial discrimination against African-American drivers. While African-American passengers generally tipped less, on average they also tipped black drivers approximately one-third less than they tipped white drivers.

The propensity to "stiff"- by which we mean to leave no tip-was particularly racialized. African-American drivers were $80 \%$ more likely to be stiffed than white drivers (28.3\% versus $15.7 \%)$. And African-American passengers were almost four times more likely than white passengers to leave no tip at all (39.2\% versus $10.6 \%)$.

Because we do not observe (and hence cannot accurately control for) passenger wealth or income, it is possible that passenger poverty instead of race may be driving this result. But cab drivers cannot directly observe

4. There have been some important sociological studies analyzing consumer preferences for dealing with sellers of particular ethnic or racial groups. See ST. CLAIR DRAKE \& HORACE R. CAYTON, BlACK METROPOLIS: A STUDY OF NEGRO LIFE IN A NORTHERN CITY (1945); Jennifer Lee, From Civil Relations to Racial Conflict: Merchant-Customer Interactions in Urban America, 67 AM. SOC. REV. 77 (2002); Albert E. McCormick \& Graham C. Kinloch, Interracial Contact in the Customer-Clerk Situation, 126 J. SOC. PSYCHOL. 551 (1986). More recently, there has been discussion of the rise of "for us, by us" (FUBU) consumerism, which at heart is a movement of race-contingent consumer choice. Jerre B. Swann, Sr. et al., Trademarks and Marketing, 91 TRADEMARK REP. 787, 802 (2001) ('FUBU ('For Us, By Us') brand clothing became popular in the African-American community in part by tapping into the sense of cultural unity and 'authenticity' that wearing the brand fostered."). But these studies tend to be qualitative, failing to measure the degree of preference or to conduct statistical tests of its significance. 
passenger wealth either. They can only infer the amount of a prospective tip based on visible characteristics, like passenger demographics, and transactional factors, like weather, pickup location, etc. Thus, our finding that African-American and Hispanic passengers tend to tip less can be interpreted as an estimate of the inferences that would be made by a driver who was a "statistical discriminator."

Our limited data allow us to estimate what kind of statistical inferences a cab driver could make about the size of the likely tip and fare given the observable characteristics of passengers. This Essay cashes out the inferences that a retail seller would make about its potential customers. Our "statistical discrimination" regressions suggest that "rational" drivers might expect to earn a $56.5 \%$ lower tip from an African-American passenger than from a white passenger (after controlling for a host of nonracial observable characteristics). Overall, a driver in our data should have expected about 9\% less revenue when stopping to pick up an African-American passenger (relative to a white passenger).

This result has policy relevance because such driver inferences may play a role in the well-documented tendency of drivers to refuse to pick up minority passengers. ${ }^{5}$ The data suggest that at least a portion of driver-side discrimination may be caused neither by animus nor by (rational or irrational) statistical inferences about crime but instead by inferences about how much passengers of different races are likely to tip. Indeed, we show that this revenue effect is orders of magnitude greater than any rational inferences that might be made about the propensities of passengers of different races to rob cab drivers.

Several caveats, however, are in order before accepting these interpretations of the data. First, the data were based on cab drivers' reports. $\mathrm{Cab}$ drivers' racial stereotypes or preconceptions may have led them to systematically underreport black-passenger (or overreport white-passenger) tips. Second, we do not have strong controls for driver quality. Lower tips by African-American passengers might be explained by a general tendency of passengers to give lower tips for poorer service, coupled with drivers providing inferior service to African-American passengers. We respond to these (and other) alternative hypotheses below by bringing to bear additional pieces of evidence.

If we tentatively accept the finding of customer discrimination against African-American drivers, it is natural to ask, "Why?" The data are not well suited to answer this question, but they do contain some clues. For example, the higher propensity of passengers to stiff black drivers seems more consistent with a theory of conscious decisionmaking. Because driver

5. See infra Subsection VII.B.2. 
allocation was more or less random, this passenger discrimination cannot be driven simply by the existence of some passengers who never tip. Rather, there seem to be passengers who are more likely to decide not to tip African-American drivers.

In contrast, another portion of the overall driver disparity may more likely reflect unconscious disparate treatment. Passengers tend to round up their tips (to the nearest dollar above their target level) more often when tipping white drivers than when tipping black drivers $32.3 \%$ versus $24.0 \%){ }^{6}$ When confronted with a last-second decision (based on the final fare) about whether to round up or round down, even passengers who believe they are hardwired fifteen-percent tippers may in practice unconsciously allow the driver's race to impact their rounding decision.? When we decompose the overall racial disparity in tips received, we find that racial disparities in stiffing and rounding account respectively for about $27 \%$ and $36 \%$ of the overall disparity.

The word "TIP" is thought by some to have originated in British pubs, where signs with just these three letters were posted on boxes as a reminder that gratuities were welcome; the letters were an acronym for the phrase "To Insure Promptness." But the evidence from this Essay is suggestive of a new acronym: "To Insure Prejudice." Tipping may facilitate prejudice in two different ways: (1) It allows customers to discriminate against minority drivers, and (2) it gives cab drivers a revenue-based incentive to refuse to pick up minority passengers.

Our two core findings give rise to a single normative implication: Government-mandated tipping (via a "Tip Included" decal prominently posted in cabs) might be used to reduce two different types of disparate racial treatment. First, mandated tipping would directly reduce the

6. These percentages are taken over all fares, so that $24.0 \%$ of all black-driver fares are rounded up to the nearest dollar above the passenger's target level.

7. This finding parallels the results for the Implicit Association Tests (IATs), which analogously suggest that unconscious racial influences affect timed sorting decisions. See AYRES, supra note 1, at 419 (discussing the legal relevance of IATs); Anthony G. Greenwald et al., Measuring Individual Differences in Implicit Cognition: The Implicit Association Test, $74 \mathrm{~J}$. PERSONALITY \& SOC. PSYCHOL. 1464 (1998).

8. See E.L. KonigSBuRG, The View from Saturday 126 (1997); David Templeton, Tipper Lore: Is It Service or Custom That Tips Scales?, SONOMA COUNTY (Cal.) INDEP., Oct. 24, 1996, available at http://www.metroactive.com/papers/sonoma/10.24.96/dining-9643.html ("An oftrepeated story is that tipping [is] supposedly an acronym for 'to insure promptitude'. . .."). But this acronym etymology is probably apocryphal:

In many foreign languages, words for "tip" are associated with drinking, because in many countries the tip began as a gratuity to enable the tippee to buy himself a drink. In French "pourboire" means literally "for drink;" the German "trinkgeld" is "drink money;" the Spanish "propina" is from "propinar," meaning invite to drink; Russia's "nachai" is the equivalent of "for tea;" and the Chinese "cumshaw" is "tea money." It may be reasonable to surmise the word tip is a short form of "tipple"-to drink.

KERRY SEGRAVE, TIPPING: AN AMERICAN SOCIAL HISTORY OF GRATUITIES 5 (1998). 
passenger discrimination against black drivers documented in this study. Second, mandated tipping might indirectly reduce the tendency of drivers to refuse to pick up black passengers-at least to the extent that this driver discrimination is caused by statistical inferences about differences in tipping.

There are, however, at least two reasons to pause before eliminating discretionary tipping. First, although research suggests that tips are not strongly correlated with quality of service, tipping (at least in theory) may induce better service. Second, poorer individuals, whose rides are currently subsidized by passengers who tip more, will be less able to afford the increased fares under a mandatory tipping regime. (To the extent that minority individuals tend to be less wealthy, this shift would have a disparate racial impact.)

The body of this Essay is divided into seven Parts. Part I briefly reviews the role of race in the history of tipping in the United States. Part II describes the data collected for this study. Part III presents the core results-highlighting both the racial and the nonracial determinants of cab driver tipping. Part IV presents evidence that "statistical discrimination" may cause a portion of the well-documented reluctance of drivers to serve African-American customers. Part V considers alternative, nonracial hypotheses for our findings. Part VI explores what might be causing the customer discrimination. And finally, Part VII discusses normative implications of the findings.

\section{RACE AND THE HISTORY OF TIPPING}

Tipping is a substantial component of our economy. More than thirty service professions are regularly tipped. ${ }^{9}$ Restaurant, bar, and lodging tips in the United States have been estimated at twenty-six billion dollars a year. ${ }^{10}$ The tipping norm is now broadly accepted both as a matter of equity-to increase the wages of workers in the service industry-and as a matter of efficiency - to increase the quality of service. ${ }^{11}$ People tend not to

9. Michael Lynn et al., Consumer Tipping: A Cross-Country Study, 20 J. CONSUMER ReS. 478, 482 (1993) (citing NANCY STAR, THE INTERNATIONAL GUIDE TO TIPPING (1988)).

10. Ofer H. Azar, The Social Norm of Tipping: A Review 1 (Sept. 5, 2002) (unpublished manuscript), available at http://ssm.com/abstract $=370081$.

11. See Uri Ben-Zion \& Edi Karni, "Tip" Payments and the Quality of Service, in EsSAYS IN LABOR MARKET ANALYSIS 37 (Orley C. Ashenfelter \& Wallace E. Oates eds., 1977) (explicitly modeling a repeated interaction between a customer who chooses how much to tip and a service agent who chooses how much effort to provide to show how a marginal reward for effort could induce the service agent to provide more than the minimal effort level). Researchers have explored a variety of server strategies that can enhance restaurant tipping:

In one well-known 1984 experiment, researchers found that a waitress who touched her customers, whether male or female, on the hand or shoulder when asking if 
know what percentage of income their parents give to charity, but they know their parents' tipping percentage. ${ }^{12}$ Indeed, parents often explicitly tell their children how much they should tip in various settings. ${ }^{13}$

But what is less well known is that the social practice of tipping was much more controversial 100 years ago. Critics referred to the practice as "un-American" and incompatible with democracy. ${ }^{14}$ Former Yale law professor William Howard Taft was the "patron saint of the anti-tip crusade," 15 and Ralph Waldo Emerson roundly condemned the practice: "I sometimes succumb and give the dollar, yet it is a wicked dollar which by and by I shall have the manhood to withhold."16 Tipping was attacked as bribery and as "training school of graft."17

In the early twentieth century, seven states passed anti-tipping statutes that to varying degrees outlawed the practice. ${ }^{18}$ Today many patrons and workers in the service industry look on the tipping practice not only as nonstigmatizing but, indeed, as a worker's entitlement for work well done. At the turn of the last century, in contrast, tipping was often viewed as a marker of degradation. Both the giving and the receiving of tips were perceived as an acceptance of the recipient's inferiority. ${ }^{19}$ In The Itching

the meal was all right, raised her tips to 14 percent, from 11 percent. . . [Tips are also increased by] crouching at the table when taking an order instead of standing upright or, if the server is a woman, putting a smiley face on the bill. For male waiters, the smiley face actually cuts tips.

William Grimes, Tips: Check Your Insecurity at the Door, N.Y. TIMES, Feb. 3, 1999, at F1.

12. BARRY NALEBUfF \& IAN AYRES, WHY NOT?: HOW TO USE EVERYDAY INGENUITY To SOLVE PROBLEMS BIG AND SMALL 101 (2003).

13. Id. at 101.

14. SEGRAVE, supra note 8, at 5-6 ("What, may I ask, is more un-American than tipping? It doesn't belong in American society; it doesn't belong in a democracy. It is a product of lands where for centuries there has been a servile class." (internal quotation marks omitted)); see also William R. SCOTT, THE ITCHING PALM: A StUdY OF THE HABIT OF TipPING IN AMERICA 38 (1916) ("In the American democracy to be servile is incompatible with citizenship. Every tip given in the United States is a blow at our experiment in democracy.").

15. Taft an Anti-Tipper, N.Y. TIMES, June 20,1908 , at 2 (" $[\mathrm{N}]$ ever a tip did he give. I understand that he thinks he has paid for the work when he gives the regular price, and I guess he is right." (quoting Taft's barber)).

16. The Point of View: Regulating Tips, SCRIBNER'S MAG., Feb. 1909, at 250, 252 (internal quotation marks omitted).

17. SCOTT, supra note 14 , at 42 . In 1920, William Rufus Scott launched the Commercial Bribery and Tipping Review. SEGRAVE, supra note 8, at 72. Scott argued that tipping was not only a form of bribery whereby one customer sought unfair advantage over another but also a breeding ground for social corruption more generally. He wondered, "Will a messenger boy who thinks that the public owes him gratuities develop into a man with sound morals?" SCOTT, supra note 14, at 42. "There is a direct connection between corruption in elections and the custom of tipping. The man who lives upon tips will not see the dishonesty of selling his vote ...." Id. at 43.

18. Stephanie Cook, A History of 'Handing it Over,' Christian SCI. MONITOR, Oct. 23, 2000, at 14; see also SEGRAVE, supra note 8, at 29.

19. The predecessor to The Oxford English Dictionary in 1916 defined "tip" as "[a] small present of money given to an inferior." [Ti-Tz] A NEW ENGLISH DICTIONARY ON HISTORICAL PRINCIPLES; Founded MAINLY ON THE MATERIALS COLleCTEd BY THE PHILOLOGICAL SOCIETY 60 (James A.H. Murray ed., 1888, 1916). "[T]ipping makes the daily income of the 
Palm, a 1916 manifesto against the practice, William Rufus Scott said that tipping is a form of "Flunkyism" defined as "a willingness to be servile for a consideration., 20

This degradation conception of tipping was intimately tied to race. Kerry Segrave has taken the lead in excavating this history:

[A] Gunton's Magazine article in $1896 \ldots$ remarked that in the United States "we have been comparatively free from this offensive semi-mendicancy." However, tipping was a growing custom among a certain class of laborers such as domestic servants, coachmen, barbers, waiters, and railroad porters: "It will be observed that these occupations are nearly all filled by foreigners and negroes who for the most part have been reared under the patronizing and semifeudal influences of paternal or ante-wage condition[s]." Centuries of slavery had left blacks in menial jobs while Europeans were menial workers due to the "aristocratic, patronizing conditions of Europe."21

For some, the practice of tipping was intimately connected to the perceived inferiority of African Americans. In 1902, for example, a Southern journalist named John Speed remarked,

I had never known any but negro servants. Negroes take tips, of course; one expects that of them-it is a token of their inferiority. But to give money to a white man was embarrassing to me. I felt defiled by his debasement and servility. Indeed, I do not now comprehend how any native-born American could consent to take a tip. Tips go with servility, and no man who is a voter in this country by birthright is in the least justified in being servile. ${ }^{22}$

Scott also condemned tipping as a form of servility and compared it to slavery in the United States: "The relation of a man giving a tip and a man accepting it is as undemocratic as the relation of master and slave."23

The modern tipping norm was incubated in a history rife with explicit racism-as can be seen in the public prominence given to a seemingly insignificant vignette reported by Segrave. In 1907, a South Carolina

worker dependent upon his subservience to the passing humor of the customer. It promotes fawning and sycophancy, and kills dignity and independence." SEGRAVE, supra note 8 , at 72 (internal quotation marks omitted).

20. SCOTT, supra note 14 , at 7 .

21. SEGRAVE, supra note 8, at 6 (quoting Economic Effects of Tipping, 11 GUNTON'S MAG. $13,14-15(1896))$.

22. John Gilmer Speed, Tips and Commissions, 69 LIPPINCOTT'S MONTHLY MAG. 742, 748 (1902).

23. ScOTT, supra note 14 , at 50 . 
senator, well known for his claim never to "tip[] a nigger," tipped a black porter in a Nebraska hotel. ${ }^{24}$ The porter "joked that he would have the quarter made into a watch charm."25 A New York Times editor defended the senator's no-tipping policy as "not meanness," but rather "a matter of principle."26

The practice of tipping-far from being perceived as a way of increasing the pay of service workers-was frequently seen as an employer strategy for exploiting workers, particularly black workers. The Pullman Company in particular was repeatedly singled out for fostering the tipping norm for its all-black workforce as a way of economizing on its wage bill. In 1914, when the Railroad Commission of California asked why the company only hired blacks from the South, an executive explained, "[T]he Southern negro is more pleasing to the traveling public. He is more adapted to wait on people and serve with a smile."27 The St. Louis Republic newspaper concluded that "[i]t was the Pullman company which fastened the tipping habit on the American people and they used the negro as the instrument to do it with." ${ }^{28}$ Pullman made public the fact that its AfricanAmerican porters were poorly paid so that the public would pay them instead.

When the Pullman porters organized into the Brotherhood of Sleeping Car Porters in 1925, one of the first things they did was to petition the Interstate Commerce Commission for an order prohibiting tips. The New York Times account of the petition noted, "Only Negroes, many of them exslaves, were employed as porters. This, says the petition, caused the work to be looked on as 'menial and servile' and led to the giving and taking of gratuities." 29 That porters would ask the ICC to prohibit a form of their compensation is remarkable. True, a tipping prohibition would put pressure on the Pullman Company to pay higher wages. But it is hard to imagine that the increase in wages would more than offset the loss of tipping income. ${ }^{30}$ The petition may therefore have had a noneconomic motive. Even if the prohibition would not increase their net incomes, the black porters' union might have wanted it nonetheless-possibly to increase the dignitary dimensions of their employment. They too may have seen the receiving of

24. SEGRAVE, supra note 8 , at 11 (internal quotation marks omitted).

25. Id.

26. Id. (internal quotation marks omitted).

27. SCOTT, supra note 14 , at 107 (internal quotation marks omitted).

28. Id. at 112 (internal quotation marks omitted).

29. Porters Assail Tipping, N.Y. TIMES, Nov. 27, 1927, at 23 (quoting the petition).

30. One possibility is that making transparent the low net income of the porters would have induced the government to require an increase in their pay. 
tips as "a token of their inferiority" and wanted to move away from an equilibrium of having to scrape and bow for their living. ${ }^{31}$

This brief detour does not begin to serve as a full history of tipping practices or their intersections with race. ${ }^{32}$ But it may somewhat destabilize and problematize current norms about the inherent desert of service workers to tips. We will pick up this history again both when we discuss the tendency of minority passengers to tip less than whites and when we discuss our proposal to discourage discretionary tipping.

\section{DESCRIPTION OF DATA}

In April and May 2001, we collected tipping data from 1066 surveys completed by twelve different New Haven medallion taxicab drivers (six black men, four white men, and two "other minority" 33 men). As of the 2000 Census, the City of New Haven had a total population of 123,626. Hispanics comprised $21.4 \%$ of the city's population. Of those residents, both Hispanic and non-Hispanic, reporting only one race $(96.1 \%$ of the total), $37.4 \%$ were African American and $43.5 \%$ were white. ${ }^{34}$ As with many cities, the surrounding suburbs are generally whiter and wealthier. New Haven County had a total population of 824,008 in 2000 . Hispanics made up $10.1 \%$ of the county as a whole; blacks, $11.3 \%$; and whites, $79.4 \%{ }^{35}$ The median household income in 1999 was $\$ 29,604$ in the city versus $\$ 48,834$ in the county. ${ }^{36}$

31. We find no explicit historical treatment of the way in which the contemporary view of tipping as signaling a server's worth came to dominate the earlier degradation conception. Nevertheless, Segrave's history suggests an intermediate state-that by the 1950s tipping was regarded more as nuisance than as moral dilemma.

32. There has been very little historical study of the racial dimension of tipping, particularly beyond the early part of the twentieth century when tipping was explicitly linked to slavery. Much more research is necessary to draw out the full implications of this history.

33. In this "other minority" racial category, one of the cab drivers self-reported his race as being "Arab (Franco-Moroccan)" and the other "Asian (Indian)." The racial composition of New Haven cab drivers (who are predominantly white or black) differs markedly from other cities'. See, e.g., Katherine Zoepf, In Chelsea, a Little Dal Spells Home, N.Y. TIMES, Feb. 16, 2003, § 14, at 4 ("A spokesman for the New York City Taxi and Limousine Commission estimates that 70 percent of the city's 100,000 cabbies are from the Indian subcontinent.").

34. Census Bureau, American FactFinder, http://factfinder.census.gov/home/saff/ main.html?_lang=en (search "Get a Fact Sheet for your community" for "New Haven, Connecticut" and follow "New Haven city, Connecticut" link) (last visited Apr. 30, 2005).

35. Id.

36. Compare id. with Census Bureau, American FactFinder, http://factfinder.census.gov/ home/saff/main.html?_lang=en (search "Get a Fact Sheet for your community" for "New Haven, Connecticut" and follow "New Haven County, Connecticut" link) (last visited Apr. 30, 2005). 
As do other localities, ${ }^{37}$ New Haven regulates both the number of taxis on the road and the price taxis can charge. Taxis are common carriers that have a duty to "service all" customers. ${ }^{38}$ There are about 140 medallions in New Haven, predominantly owned by the MetroCab Company. With only a few exceptions, the cabs in our study were leased from MetroCab on a fixed-cost basis-meaning that the drivers were the residual claimants of all revenues, including tips.

The drivers were instructed to complete the surveys immediately after dropping off their passengers and were subsequently paid (by us) one dollar per survey. The amount tipped was calculated as the difference between the amount due (the fare) and the total amount paid by the passenger to the driver. Drivers reported information on passenger and driver profiles, including sex, race, age, passenger dress (as a proxy for wealth), and driver experience. Drivers were also asked to indicate if they knew the passengers, if the passengers were regular clients, if conversation took place between them, if the pickup was in response to a call, and if the passenger paid cash. Other data included pickup and drop-off neighborhoods, travel times, day of the week, time of day, temperature, and weather.

Table 1 reports summary statistics for this survey data set.

37. See Lee A. Harris, Taxicab Economics: The Freedom To Contract for a Ride, 1 GEO. J.L. \& PUB. POL'Y 195, 200 (2002). Harris notes that the main constraints in the taxicab industry can be schematized, loosely, into two categories - entry controls and price restrictions. Id. at 201 . The artificial restriction of supply has caused New York medallions to be worth well in excess of $\$ 150,000$. Marcus Cole has suggested that the medallion system reduces competition and allows drivers more leeway in refusing to pick up minority passengers. Marcus Cole, Medallion Monopoly Drives Taxicab Racism, LIBERTY \& L. (Inst. for Justice, Washington, D.C.), Feb. 2000, at 4 .

38. In many jurisdictions, the "service all" rule is enforced by prohibiting taxicab drivers from asking the destination of passengers until they have entered the vehicle. Harris, supra note 37, at 209. In New Haven, dispatchers inquire about destination but do not pass that information along to drivers. Some drivers, however, circumvent the dispatchers by distributing personal business cards with cell phone numbers. During our testing process, one such driver declined to pick up a tester after inquiring as to drop-off location. 


\section{TABLE 1. SUMMARY STATISTICS}

\begin{tabular}{||l|c|c|c|c|c||}
\hline Continuous variables & Observations & Mean & $\begin{array}{c}\text { Standard } \\
\text { deviation }\end{array}$ & Minimum & Maximum \\
\hline Tip (\$) & 1059 & 1.22 & 2.25 & -5 & 27.5 \\
\hline Tip as \% of fare & 1059 & 0.16 & 0.27 & -0.14 & 5.22 \\
\hline Stiffing rate & 1059 & 0.24 & 0.43 & 0 & 1 \\
\hline Travel time (minutes) & 952 & 9.94 & 11.89 & 1.5 & 200 \\
\hline Travel distance (miles) & 943 & 4.59 & 7.73 & 0.2 & 90 \\
\hline Amount due (\$) & 1064 & 9.26 & 11.51 & 2.5 & 150 \\
\hline Amount paid (\$) & 1059 & 10.48 & 12.86 & 3 & 170 \\
\hline Temperature ( ${ }^{(0)}$ & 1044 & 52.25 & 10.38 & 28 & 80 \\
\hline Passenger age ${ }^{39}$ & 1039 & 32.77 & 13.45 & 5 & 85 \\
\hline Driver age & 1016 & 39.78 & 7.95 & 24 & 51 \\
\hline $\begin{array}{l}\text { Driver experience } \\
\text { (weeks) }\end{array}$ & 1066 & 62.69 & 53.47 & 2 & 192 \\
\hline
\end{tabular}

\begin{tabular}{|c|c|c|c|c|}
\hline Indicator variables $^{4 \theta}$ & Observations & Percentage $\mathrm{e}^{41}$ & Mean tip & $\begin{array}{c}\text { Mean tip } \\
\text { percentage }\end{array}$ \\
\hline \multicolumn{5}{|l|}{ Passenger sex: } \\
\hline Female & 506 & $47.5 \%$ & 0.97 & $15.5 \%$ \\
\hline Male & 443 & $41.6 \%$ & 1.46 & $16.6 \%$ \\
\hline \multicolumn{5}{|l|}{ Passenger dress: } \\
\hline Below average & 41 & $3.9 \%$ & 0.79 & $12.8 \%$ \\
\hline Average & 858 & $80.5 \%$ & 1.16 & $15.1 \%$ \\
\hline Above average & 146 & $13.7 \%$ & 1.74 & $21.8 \%$ \\
\hline Respond to call & 648 & $68.9 \%$ & 1.24 & $15.9 \%$ \\
\hline Luggage & 196 & $18.4 \%$ & 1.61 & $15.3 \%$ \\
\hline
\end{tabular}

39. For multiple-passenger rides, drivers were instructed to record information only for the passenger who paid the fare.

40. Among those variables not listed here are indicators for neighborhood and address, day of the week, time of day, fare type (on the dollar; $\$ 0.25, \$ 0.50$, and $\$ 0.75$ above the dollar), individual driver, and categorical variables derived from continuous variables.

41. Variable percentages may not add up to 100 if the variable is undefined for any observations. 


\begin{tabular}{|l|c|c|c|c|}
\hline Regular customer & 188 & $17.6 \%$ & 1.87 & $25.0 \%$ \\
\hline Acquaintance & 254 & $23.8 \%$ & 1.85 & $24.6 \%$ \\
\hline Conversation & 720 & $67.5 \%$ & 1.37 & $17.3 \%$ \\
\hline Rain or snow & 27 & $2.5 \%$ & 2.28 & $37.8 \%$ \\
\hline Cash & 935 & $98.1 \%$ & 1.21 & $16.5 \%$ \\
\hline
\end{tabular}

Overall, the average tip was $\$ 1.22$, and the average tip as a percentage of fare was $15.8 \%{ }^{42}$ The percentage of passengers who left no tip (the "stiffing rate") was $23.8 \%{ }^{43}$ The data contain substantial numbers of both male and female passengers and are also. well balanced with regard to black- and white-driver observations ( $n=517$ and 450 , respectively), ${ }^{44}$ which aids greatly in developing statistically reliable tests of whether consumers discriminate in tipping.

Unlike New York or Washington cab drivers, who obtain a substantial portion of their fares from passengers who hail them from the street, New Haven cab drivers predominantly obtain fares by responding to radio calls or by waiting at designated stands (for example, at the New Haven train station or airport). More than two-thirds of our observations came from responses to a dispatcher's call, and the remainder came mostly from drivers waiting their turn at cab stands. Because both the dispatcher and the cab stand pickups are distributed on a queued basis and because New Haven drivers do not have as much discretion in turning down fares as hailed cab drivers, the structure of service provision tends to randomize driver-customer pairings. The tendency toward randomization increases the power of our test of consumer discrimination.

\section{RESULTS}

While we ultimately rely on multivariate regression analysis, our central results are suggested by simply calculating the race-specific means for the tip amount.

42. Here and throughout this Essay, the average dollar and percentage tip figures reflect the full data set, including zero- and negative-tip observations.

43. There were only seven negative tips in our data. We retained them as examples of instances where the passenger may not have had sufficient funds to pay the entire fare. None of the core results change if these observations are omitted.

44. This did not occur by chance-drivers were recruited with the goal of achieving balance between black and white drivers. Accordingly, the data are not necessarily representative of the racial mix of cab drivers in New Haven. 


\section{A. Lower Tips for Minority Drivers}

The central evidence of consumer discrimination is summarized in Table 2.

TABle 2. AVERAge TiPs ANd TIP Percentage By DRIVER RACE

\begin{tabular}{|l|c|c|c|c||}
\hline \multirow{2}{*}{ Driver race } & \multirow{2}{*}{ Mean tip } & \multirow{2}{*}{$\begin{array}{c}\text { Mean tip } \\
\text { percentage }\end{array}$} & \multicolumn{2}{|c|}{ Race disparity ratios $^{45}$} \\
\cline { 4 - 5 } & & & Tip & Tip percentage \\
\hline White & $\$ 1.54$ & $20.3 \%$ & - & - \\
\hline Black & $\$ 1.02$ & $12.6 \%$ & 0.66 & 0.62 \\
\hline Other & $\$ 0.76$ & $12.4 \%$ & 0.50 & 0.61 \\
\hline
\end{tabular}

White drivers are tipped substantially more than black (or other) drivers whether measured either in terms of the average tip amount or the average tip percentage. White drivers were tipped $61 \%$ more than black drivers (20.3\% versus $12.6 \%)$ and $64 \%$ more than our "other minority" drivers (20.3\% versus $12.4 \%$ ). Put simply, passengers systematically tipped white drivers substantially more than nonwhite drivers.

Disparate treatment in tipping can also be seen in passengers' disparate propensities to stiff drivers of different races.

TABLE 3. STIFFING RATE BY DRIVER RACE

\begin{tabular}{||l|c|c|}
\hline \multicolumn{1}{|c|}{ Driver race } & Stiffing rate & Race disparity ratios \\
\hline White & $15.7 \%$ & - \\
\hline Black & $28.3 \%$ & 1.80 \\
\hline Other & $36.4 \%$ & 2.31 \\
\hline
\end{tabular}

Table 3 shows that the rate at which white drivers were stiffed $(15.7 \%)$ was far less than that of nonwhite drivers $(28.3 \%$ and $36.4 \%$ for black and "other minority" drivers, respectively). Black drivers were $80 \%$ more likely to be stiffed than white drivers (and our "other minority" drivers were $131 \%$ more likely).

45. Disparity here and in all subsequent tables is defined as the given statistic divided by the White statistic. 
B. Lower Tips by Minority Passengers

The second racial effect that can be seen in the aggregate data concerns the propensity of different racial groups to tip different amounts.

Table 4. Average Tips and TipPINg Percentage by Passenger Race

\begin{tabular}{|c|c|c|c|c|}
\hline \multirow{2}{*}{ Passenger race } & \multirow{2}{*}{ Mean tip } & \multirow{2}{*}{$\begin{array}{l}\text { Mean tip } \\
\text { percentage }\end{array}$} & \multicolumn{2}{|c|}{ Race disparity ratios } \\
\hline & & & Tip & Tip percentage \\
\hline White & $\$ 1.82$ & $21.6 \%$ & - & - \\
\hline Black & $\$ 0.60$ & $9.2 \%$ & 0.33 & 0.42 \\
\hline Hispanic & $\$ 0.81$ & $12.0 \%$ & 0.44 & 0.55 \\
\hline Asian & $\$ 1.02$ & $16.2 \%$ & 0.56 & 0.75 \\
\hline Other & $\$ 0.84$ & $10.7 \%$ & 0.46 & 0.49 \\
\hline
\end{tabular}

Table 4, for example, shows that the average tipping percentage of black passengers in our data was only $42 \%$ of the average tipping percentage of white passengers $(9.2 \%$ versus $21.6 \%)$. The tipping percentage of Hispanic passengers was only slightly more than half of the white-passenger tipping percentage ( $12.0 \%$ versus $21.6 \%$ ). And Asian passengers tipped only $75 \%$ of the white-passenger tipping percentage ( $16.2 \%$ versus $21.6 \%)$.

As before, the racial disparity in the average tip amount or tip percentage can also be seen in the different propensities of passengers to stiff drivers.

TABLE 5. STIFFING RATE BY PASSENGER RACE

\begin{tabular}{|l|c|c|}
\hline \multicolumn{1}{|c|}{ Passenger race } & Stiffing rate & Race disparity ratios \\
\hline White & $10.6 \%$ & - \\
\hline Black & $39.2 \%$ & 3.69 \\
\hline Hispanic & $34.3 \%$ & 3.23 \\
\hline Asian & $15.8 \%$ & 1.49 \\
\hline Other & $35.7 \%$ & 3.36 \\
\hline
\end{tabular}

Table 5 shows that black passengers in our data were 3.7 times more likely to stiff than white passengers, and Hispanic passengers were 3.2 times more 
likely (39.2\% and $34.3 \%$ stiffing rates for blacks and Hispanics respectively versus only $10.6 \%$ for whites).

It is important to emphasize, however, that the racial disparities reported in Tables 4 and 5 (as well as those uncovered in Tables 2 and 3) are just first cuts at the data. These tables do not control for other variables-such as the socioeconomic status of the passenger or the service quality of the driver-that might be driving the result. These issues and others will be explicitly discussed in considering alternative hypotheses in Part IV.

But, as emphasized in the Introduction, these passenger-race results may have policy relevance even without controlling for any nonracial factors. A driver who "irrationally" makes inferences based solely on a passenger's race would be apt to infer that black or Hispanic passengers tip only half as much as whites-and this inference might lead the driver to discriminate against these passengers. We will return to this issue more formally in Part VI.

\section{Driver and Passenger Racial Intersections}

A natural question to ask is whether minority passengers tip black drivers less than white drivers. Table 6 suggests that they do.

Indeed, Table 6 shows that, measured on a percentage basis, the driverrace disparity was nearly identical for black and white passengers. White passengers tipped white drivers $67 \%$ more than black drivers $(26.7 \%$ versus $17.9 \%$ ), while black passengers tipped white drivers $67 \%$ more than black drivers $(11.0 \%$ versus $7.4 \%)$. To be clear, black passengers generally tipped less than white passengers, but black passengers tipped black drivers even less. Thus, at least with regard to the two largest racial groups in our sample, ${ }^{46}$ there seem to be largely independent passenger- and driver-race effects. $^{47}$

46. Observations from Hispanic passengers produced the largest driver disparity-with the tipping percentage for white drivers being $146 \%$ higher than the tipping percentage for black drivers $(17.5 \%$ versus $7.1 \%$ ). Asian passengers were the only group to tip black drivers a higher percentage than white drivers $(18.1 \%$ and $16.1 \%$ for black and white drivers, respectively).

47. Analogous numbers concerning the average amount tipped can be found at http://www yalelawjoumal.org. The results are qualitatively similar to those in Table 6: Again, black and Hispanic passengers, like whites, tipped black cab drivers less. 
TABle 6. AVerage Tipping Percentage BY PASSENGER AND DRIVER RACE

\begin{tabular}{|c|c|c|c|c|}
\hline Passenger race & Driver race & $\begin{array}{l}\text { Mean tip } \\
\text { percentage }\end{array}$ & Observations & Race disparity \\
\hline \multirow{3}{*}{ White } & White & $26.7 \%$ & 224 & - \\
\hline & Black & $17.9 \%$ & 222 & 0.67 \\
\hline & Other & $13.2 \%$ & 34 & 0.49 \\
\hline \multirow{3}{*}{ Black } & White & $11.0 \%$ & 112 & - \\
\hline & Black & $7.4 \%$ & 176 & 0.67 \\
\hline & Other & $13.1 \%$ & 28 & 1.19 \\
\hline \multirow{3}{*}{ Mispante } & White & $17.5 \%$ & 57 & - \\
\hline & Black & $7.1 \%$ & 63 & 0.41 \\
\hline & Other & $11.3 \%$ & 17 & 0.65 \\
\hline \multirow{3}{*}{ Asian } & White & $16.1 \%$ & 42 & - \\
\hline & Black & $18.1 \%$ & 36 & 1.12 \\
\hline & Other & $12.3 \%$ & 17 & 0.77 \\
\hline \multirow{3}{*}{ Other } & White & $14.8 \%$ & 6 & - \\
\hline & Black & $11.0 \%$ & 5 & 0.74 \\
\hline & Other & $1.8 \%$ & 3 & 0.12 \\
\hline
\end{tabular}

The tendency of minority passengers to join in the larger pattern of passenger discrimination against minority drivers can also be seen in an analysis of stiffing rates.

Table 7 shows that white passengers are almost twice as likely to stiff black drivers as white drivers (12.2\% versus $6.3 \%$ ). Again, the behavior of minority passengers qualitatively mirrors this disparity. From Table 5, we already know that black passengers are more likely to stiff drivers than white passengers, but Table 7 shows that black passengers are almost a third more likely to stiff black drivers than white drivers $(43.2 \%$ versus $33.0 \%$ ) and that Hispanic passengers are $88 \%$ more likely to stiff black drivers than white drivers ( $42.9 \%$ versus $22.8 \%$ ). 
TABLE 7. STiffing RATE By PASSENGER AND DRIVER RACE

\begin{tabular}{|c|c|c|c|c|}
\hline Passenger race & Driver race & Stiffing rate & Observations & Race disparity ratios \\
\hline \multirow{3}{*}{ White } & White & $6.3 \%$ & 224 & - \\
\hline & Black & $12.2 \%$ & 222 & 1.95 \\
\hline & Other & $29.4 \%$ & 34 & 4.71 \\
\hline \multirow{3}{*}{ Black } & White & $33.0 \%$ & 112 & - \\
\hline & Black & $43.2 \%$ & 176 & 1.31 \\
\hline & Other & $39.3 \%$ & 28 & 1.19 \\
\hline \multirow{3}{*}{ Hispanic } & White & $22.8 \%$ & 57 & - \\
\hline & Black & $42.9 \%$ & 63 & 1.88 \\
\hline & Other & $41.2 \%$ & 17 & 1.81 \\
\hline \multirow{3}{*}{ Asian } & White & $9.5 \%$ & 42 & - \\
\hline & Black & $13.9 \%$ & 36 & 1.46 \\
\hline & Other & $35.3 \%$ & 17 & 3.71 \\
\hline \multirow{3}{*}{ Other } & White & $33.3 \%$ & 6 & - \\
\hline & Black & $20.0 \%$ & 5 & 0.60 \\
\hline & Other & $66.7 \%$ & 3 & 2.00 \\
\hline
\end{tabular}

\section{Regression Analysis}

The disparities reported in the previous tables, however, are provided only for heuristic purposes. Without more, we cannot know whether the results will be robust until we control for a host of nonracial factors that might influence the amount that passengers tip. The results of multivariate regression analysis are presented in the Appendix. This Section summarizes the most important results.

After controliing for random driver effects and a host of time, manner, and place effects, our various models suggest that the customer discrimination result is quite robust. Adding additional variables to the regression does not materially impact the size or statistical significance of the driver-race variables. For the most complete regression, we find that black drivers are tipped 9.1 percentage points less than white drivers (and that this result is statistically significant at the $1 \%$ level). 
The finding that minorities tip systematically less, in contrast, is not as robust to the inclusion of additional right-hand-side control variables. The size of the coefficients becomes smaller as additional controls are added. For the most complete regression, the size of the black-passenger effect is diminished to 9 percentage points (from 11.7 percentage points in the least complete regression model). ${ }^{48}$

While 9 percentage points is still substantial, the larger point here is that even our most complete specification contains only poor controls for the socioeconomic class of the passenger (above- or below-average dress and characteristics of pickup and drop-off locations). With better controls, the seeming tendency of minorities to tip less might simply become a tendency of poorer people to tip less.

\section{TESTS OF DRIVER “STATISTICAL DISCRIMINATION” INFERENCES}

Our finding that minority passengers tend to tip a lower percentage and stiff more frequently was confirmed as statistically significant for blacks in all specifications. But the atsolute size of this effect was not as robust to the inclusion of additional right-hand-side controls. As additional controls are added, the size of the black-passenger coefficients in Tables 13 and 15 becomes smaller. Because we do not observe passenger wealth or income, it is possible that passenger poverty (or other omitted variables such as driver service) instead of race may really be driving this minority-passenger result.

But our limited data allow us to estimate what kind of statistical inferences a cab driver would make about the size of the likely tip and fare given the observable characteristics of the passengers. Estimating the inferences that a driver with limited information would make about the expected tipping of different racial groups is normatively relevant, because such inferences might cause drivers to refuse to pick up passengers who are perceived to be low tippers. Indeed, the next two Sections lay out evidence that (1) driver discrimination against African Americans is a serious problem and (2) at least part of these driver refusals are actuated by just this type of "statistical discrimination."

\section{A. Evidence of Driver Discrimination}

There is abundant empirical evidence that cab drivers have discriminated against African-American passengers by refusing to pick 
them up. ${ }^{49}$ A 1989 audit study sponsored by the Washington Lawyers' Committee for Civil Rights provides controlled evidence of disparate racial treatment by cab drivers. One black and one white tester stood three car lengths from each other and attempted to hail a cab in Washington, D.C. The study found that taxis were $11.2 \%$ more likely to stop for whites than blacks and that as a result blacks had to wait, on average, $27 \%$ longer for a cab to stop. ${ }^{50}$

Evidence of this "drive-by racism" can also be gleaned from broader surveys of the population. For example, an $A B C$ News poll found that a plurality of blacks $(42 \%)$ believe that taxi drivers avoid picking up blacks (only $19 \%$ of whites agree); one in six blacks (18\%) report that they have personally been refused a cab ride. ${ }^{51}$

Anecdotal evidence is in accord. Dozens of prominent African Americans have presented detailed descriptions of discrimination. For example, an incident in 1993 in which Cornel West was refused service by ten taxis in a row provoked him to write Race Matters. ${ }^{52}$ More recently, actor Danny Glover filed a complaint with the New York Taxi and Limousine Commission (TLC) after five cab drivers refused to pick up him and his daughter. ${ }^{53}$ Following newspaper reports of the Glover incident, several other prominent African-American men-including Harry Belafonte, David Dinkins, and Denzel Washington-came forward to report that cab drivers had refused to pick them up as well. ${ }^{54}$ The TLC at

49. See Cole, supra note 37. This discrimination seems particularly pronounced in cities like New York and Washington where flagging down cabs is more prevalent. In the past-and possibly as a response to driver discrimination-informal "jitney" cabs would serve AfricanAmerican neighborhoods. See Mamie Ward, A Long Cab Ride Ending, Miami HERALD, Jan. 4, 2005 , at $1 \mathrm{~A}$, available at http://www.miami.com $/ \mathrm{mld} / \mathrm{miamiherald} / 2005 / 01 / 04 / \mathrm{news} / \mathrm{local} /$ 10559093.htm? 1c; see also RUBEN SANTIAGO-HUDSON, LACKAWANNA BLUES (2001); AUGUST WILSON, JITNEY (2000). Jitneys are essentially illegal in the United States. There are, however, cities where jitney service continues, including New York and Miami. One attraction of jitneys is that the "drivers frequently live in their [passengers'] neighborhoods and are thus attuned to the unique needs of their communities." Nicole Stelle Gamett, The Road from Welfare to Work: Informal Transportation and the Urban Poor, 38 HARV. J. ON LEGIS. 173, 207-08 (2001). In this respect, jitneys may represent another manifestation of the FUBU movement.

50. Siegelman, supra note 1 , at 76-77.

51. Press Release, ABC News, Perception vs Experience in Racial Discrimination 1 (Feb. 1, 2000), available at http://abcnews.go.com/images/pdf/810Race.pdf.

52. CORNEL WEST, RACE MATTERS, at x (1993).

53. Monte Williams, Danny Glover Says Cabbies Discriminated Against Him, N.Y. TIMES, Nov. 4, 1999, at B8.

54. J.M. Shenoy, African Americans Flag Down NY Cabbies, REDIFF ON THE NET, Nov. 6, 1999, http://www.rediff.com/news/1999/nov/06us1.htm.

Several African American celebrities and senior executives working for top law and financial firms in New York were all over the media in the past 24 hours detailing their own experiences.

Makeup artist Dynode Marcie said he was in a tuxedo and waiting for a cab near the Radio City Hall in Manhattan after the Grammy Awards were given out.

Several cabbies passed by him.... 
the time was averaging seven complaints of driver discrimination each day. ${ }^{55}$

In response to the Glover incident, New York Mayor Rudy Giuliani started "Operation Refusal"- - a sting operation in which 150 undercover police were empowered to immediately impound the cabs of drivers who refused to pick up minority passengers. ${ }^{56}$ First-time offenders were fined up to $\$ 350$; third offenders could have their licenses permanently revoked. ${ }^{57}$

\section{B. Tests of Statistical Discrimination}

All in all, there seems to be overwhelming evidence of pickup discrimination by drivers against minority passengers. Indeed, while there has been a sustained debate about cab driver discrimination, the debate does not concern whether such discrimination exists but whether it is justified.

To date, the defenders of the discrimination (including many cab drivers themselves) have argued that driver discrimination is a reasonable reaction to a heightened risk that minority passengers will hurt them during the commission of a robbery. For example, in a column entitled Is It Racism, or Is It Fear?, Boston Globe columnist Jeff Jacoby noted a Bureau of Labor Statistics report that cab drivers and chauffeurs "accounted for almost one-10th of all victims of job-related homicide but less than one-half of 1 percent of the nation's work force," and argued that "[f]or most [drivers], racism isn't a reason to avoid picking up black men or driving to black neighborhoods. Prudence is." 58

Drivers emphasize that they are often not scared of minority passengers themselves but of where the passengers will ask them to go. One driver explained, "The man who gets into my cab could be the best man in the world but who knows what could happen to me after I have dropped him home?"59 By this argument, it might be rational for cab drivers to refuse to

A top Wall Street executive said that on a cold night, four cabs passed by her and her three children. When a white man appeared a few minutes later and stood a few feet ahead of her, two cabbies almost ran into each other trying to stop for him.

Id.; see also Dan Ackman, City Denies Due Process to Cabbies, NEwSDAY (N.Y.), Sept. 21, 2000 , at A51.

55. My 'Zero-Tolerance' Plan To End Taxi Discrimination, FIELDSNOTES (Manhattan Borough President C. Virginia Fields, New York, N.Y.), Winter 2000, at 3, available at http://www.cufieldsmbp.org/newsletter/fieldsnotes7.pdf.

56. See, e.g., Padberg v. McGrath-McKechnie, 108 F. Supp. 2d 177, $179-81$ (E.D.N.Y. 2000); Randy Kennedy, Cabbies Entitled to Hearings, Judge Rules, N.Y. TIMES, May 1, 2002, at B4.

57. Jeff Jacoby, Op-Ed, Is It Racism, or Is It Fear?, BOSTON GLOBE, Nov. 18, 1999, at A27.

58. Id. (internal quotation marks omitted); see also DINESH D'SOUZA, THE END OF RACISM: PRINCIPLES FOR A MULTIRACIAL SOCIETY 282 (1995).

59. Shenoy, supra note 54 (internal quotation marks omitted). 
pick up even well-dressed, elderly African-American women (who present a very low probability of committing crime themselves) if they are more likely than others to live in high-crime neighborhoods.

Of course, opponents of driver discrimination have appropriately questioned whether such discrimination might instead be driven by irrational statistical inferences, stereotypes, or more traditional forms of racial animus. ${ }^{60}$ But this Essay suggests the possibility of another dimension of statistical discrimination. Instead of (or in addition to) making inferences about crime, cab drivers might refuse to pick up minority passengers because they expect a lower tip, a lower fare, or a higher chance of having to "deadhead" back from the drop-off location without a return fare.

The idea that servers might give poorer service or refuse to serve a demographic group that they predict will give a poor tip is not new. For example, the Railroad Commission of California concluded in 1914 that "women traveling alone, because they are known to tip less 'generously' than men, receive the aid of the porters last or not at all.".61

More recently, Michael Lynn, the leading empiricist on tipping in the United States, has argued that the tendency of African Americans to tip less has created a problem for the restaurant industry: "Many waiters and waitresses believe that African-Americans tip less than Caucasians. . . As a result of that belief, many table servers dislike waiting on black customers, deliver inferior service to black guests on whom they must wait, and refuse to work in restaurants with a predominantly black clientele."

Lynn supports these claims with a variety of anecdotes from industry participants describing higher rates of server turnover for restaurants located in minority neighborhoods unless the restaurant pays a higher wage

60. See Jody D. Armour, Race Ipsa Loquitur: Of Reasonable Racists, Intelligent Bayesians, and Involuntary Negrophobes, 46 STAN. L. REV. 781 (1994). Armour has also argued that racial inferences are irrational in a more dynamic sense. A prospective decisionmaker could more accurately assess the qualities of, say, an employment candidate by fairly straightforward investigation and examination. JODY DAVID ARMOUR, NEGROPHOBIA AND REASONABLE RACISM: THE HIDDEN COSTS OF BEING BLACK IN AMERICA 51-52, 57-58 (1997) (discussing dynamic efficiency issues and the application of statistical inference by cab drivers). Race would often not be the best evidence of merit if the employer were doing her due diligence. But this dynamic critique of statistical discrimination has less force in thinking about whether cab drivers' refusal to serve is rational. A hypothetical driver approaching the curb to pick up a potential passenger has very little opportunity to acquire additional information about the passenger's qualities. The only information that the driver can access are the things that are visible from inside the cab-and it is just these variables that we collected in our surveys.

61. Tips Really Don't Go to Tiptakers, N.Y. TIMES, May 5, 1914, at 10. Similarly, a New Jersey restaurant owner pushed legislation outlawing tipping because he felt that "poor persons are at times insulted because of their small gratuities." Law To Cut Down Tips, N.Y. TIMES, Jan. 21,1911 , at 1 .

62. Michael LynN, Ethnic Differences in TIPPING: A MatTer of Familiarity 2 (Ctr. for Hospitality Research at Cornell Univ., Working Paper Series, No. 03-21-03, 2003). 
or mandates a minimum tip. ${ }^{63}$ Similarly, he quotes one commentator as suggesting, "Across America, there is a widespread belief among restaurateurs that African-Americans and members of some immigrant ethnic groups just aren't good tippers. This perception, they say, shapes strategic decisions about restaurant placement and customer policies, yet it is rarely discussed publicly because bringing it up might appear racist. ${ }^{, 64}$ In short, statistical inference may not just cause servers to discriminate, it may also have substantial repercussions on industrywide behavior.

While such statistical discrimination might be theoretically coherent, actual inferences made on this basis may be irrational or stereotyped. Indeed, psychologists have found that people who believe they are merely rational statistical race discriminators are more likely than others to harbor unconscious biases against minorities. ${ }^{65}$ To see whether tipping or one of the other revenue-based inferences might plausibly induce driver discrimination, it is helpful to assess the magnitude of the inference that rational drivers would make.

Fortunately, the data are fairly well suited for this task. While our data omit many nonracial factors that might better explain why some people leave low tips, they do contain a rich set of variables describing the information available to the cab driver. Accordingly, it was possible for us to run "observational" regressions controlling for the factors that a driver could observe about a passenger when pulling up to the curb. ${ }^{66}$

These regressions allow us to directly assess what kind of inferences drivers would make about different passenger races after controlling for other information observable at curbside. This turns a computational vice into a virtue. For these purposes, we need not be embarrassed by the omitted-variable problems that would hinder any attempt to test whether a passenger's race actually causes the passenger to tip more or less. Instead, we are interested in what kinds of inferences a driver would make given his or her limited information.

Because the salience of race may swamp the informational content of other variables, we ran the observational or statistical discrimination regressions two different ways. First, we estimated the racial inferences that

63. See, e.g., id. at 8 ("Sid Levy, who operates steakhouses in black communities in Maryland, has said that his servers make less in tips than do servers at other restaurants in the region. As a result, he experiences higher-than-typical turnover and is experimenting with additional ways of compensating his servers. ... Gerald Young, who owns an independent restaurant in Philadelphia, has said that low tips from non-white customers resulted in monthly turnover of 100 percent until he decided to add an automatic, 18-percent gratuity to every bill.").

64. Id. at 9 (internal quotation marks omitted).

65. William A. Cunningham et al., Implicit and Explicit Ethnocentrism: Revisiting the Ideologies of Prejudice, 30 PERSONALITY \& SOC. PSYCHOL. BULL. 1332 (2004).

66. In these regressions, we ignored information (such as drop-off location, conversation, and distance) that only became knowable during or after the fare. 
an "irrational" statistical discriminator would make if he saw only passenger race (and ignored all nonracial factors). Second, we estimated the racial inferences that a "rational" discriminator would make after taking into account our full panoply of curbside-observable information. To our knowledge, this is the first time that anyone has quantitatively measured the inferences that a statistical discriminator might make.

\section{TABLE 8. ESTIMATING ECONOMIC DIFFERENCES (RELATIVE TO WHITE PASSENGERS) DRIVERS COULD EXPECT BY OBSERVING THE MINORITY STATUS OF CUSTOMERS}

\begin{tabular}{|c|c|c|c|c|c|}
\hline \multirow{2}{*}{ Outcome vamables } & \multicolumn{5}{|c|}{$\begin{array}{l}\text { Irrational statistical discriminator: } \\
\text { Uncontrolled observational regressions }\end{array}$} \\
\hline & Fare $(8)$ & $T_{1} p(s)$ & $\pi p \%$ & Stiff & $\begin{array}{l}\text { Tar-suburb } \\
\text { indicator }\end{array}$ \\
\hline Passenger black & -1.791 & -1.220 & 0.405 & $\underline{\mathbf{0 . 3 1 7}}$ & -0.053 \\
\hline Passenger Iispanic & -1.873 & -1.009 & 0.350 & $\underline{0.293}$ & -0.019 \\
\hline Passenger Astan & -2.466 & -0.792 & 0.243 & 0.076 & -0.023 \\
\hline Passenger other & -0.995 & -0.977 & 0.495 & 0.320 & - \\
\hline Observations & 1064 & 1059 & - & 1059 & 835 \\
\hline$R^{2}$ & 0.0634 & 0.0624 & 一 & 0.0976 & 0.065 \\
\hline
\end{tabular}

\begin{tabular}{|c|c|c|c|c|c|}
\hline \multirow{2}{*}{ Oyteome variables } & \multicolumn{5}{|c|}{ 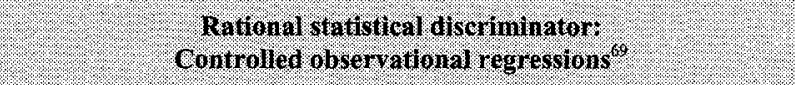 } \\
\hline & Fare $(s)$ & Wp(s) & $17 \mathrm{p} \%$ & stiff & 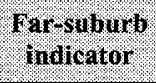 \\
\hline Passenger black & -1.093 & -0.953 & 0.466 & $\underline{0.255}$ & -0.049 \\
\hline Passorger litspanie & -0.486 & -0.711 & 0.594 & $\underline{0.228}$ & 0.002 \\
\hline passemger A ran & -0.512 & -0.436 & 0.460 & 0.087 & -0.017 \\
\hline o assenger ol her & -1.300 & -0.864 & 0.399 & 0.205 & - \\
\hline Observations & 968 & 963 & - & 958 & 436 \\
\hline$n^{2}$ & 0.1665 & 0.2281 & - & 0.2328 & 0.2116 \\
\hline
\end{tabular}

Note: Underlined coefficients are significant at the $10 \%$ level, coefficients in bold are significant at the $5 \%$ level, and coefficients underlined and in bold are significant at the $1 \%$ level.

67. Coefficients reported here are the changes in the probability resulting from discrete changes in the indicator variables from 0 to 1 .

68. Coefficients reported here are the changes in the probability resulting from discrete changes in the indicator variables from 0 to 1 .

69. Other variables in the controlled regression are passenger sex, age, and dress indicators; driver age, experience, and survey experience; repeat-passenger, acquaintance, night, late-night, snow/rain, and luggage indicators; and continuous pickup-location, categorical pickup-location, and pickup-location-specific indicator variables. 
The first two columns of Table 8 report the inferences that a driver would make about the relative size of fares and tips that different passenger races would produce. The top panel estimates that an "irrational" statistical discriminator (who sees only passenger race) would, for example, expect black passengers to generate fares that were $\$ 1.79$ lower than white passengers and to leave $\$ 1.22$ less in tips. ${ }^{70}$ And both these effects are statistically significant $(p<.05)$. The raw fare differential turns out to be bigger than the tipping differential (which is only $40.5 \%$ of the overall revenue shortfall) and hence would loom large in the inferences of this type of discriminator. Analogous results are found for Hispanic and Asian passengers. Indeed, the irrational statistical discriminator would expect the fares of Asian passengers to be almost $\$ 2.50$ less than the fares of white passengers but would expect the tips to be only $\$ 0.79$ less. $^{71}$

The bottom panel, however, tells a very different story. A rational discriminator (who takes into account not only passenger race but also nonracial factors) would come to different conclusions. Most importantly, the rational discriminator would not infer that minority passengers would have smaller fares. While the fare column shows some (more modest) shortfalls in the size of the expected fares, none of these shortfalls are statistically significant. But the tipping shortfalls remain highly statistically significant $^{72}$ and represent a higher proportion of the overall revenue shortfall. In short, while both rational and irrational discriminators would infer that minority passengers are likely to tip less, irrational discriminators would be much more concerned by revenue shortfalls caused by lower fare amounts (which statistically disappear after controlling for observable nonracial factors).

The fourth column of Table 8 reports the statistical inferences that drivers would make about the relative likelihood of being stiffed. Here, we find that both rational and irrational discriminators would make largely the same kind of inference: Black and Hispanic passengers are much more likely than white passengers to leave no tip. Indeed, the likelihood that

70. As a theoretical matter, a lower fare does not necessarily mean a less profitable fare. Because cab fares are nonlinear, starting with a fixed two-dollar amount (commonly referred to by cab drivers as "the drop"), it might be more profitable for drivers to service a larger number of small fares than a smaller number of large fares. But in New Haven, the likelihood of finding numerous small fares is low, so profitability is largely monotonic with total revenue.

71. This may be due in part to geography and housing patterns in New Haven. Recall that New Haven's suburbs are much whiter than the city. Many Asian passengers were likely Yale University students making relatively short trips between the train station and campus. See Census Bureau, supra note 34 (showing that the population of the City of New Haven is only $3.9 \%$ Asian). This hypothesis is also consistent with the diminution and loss of statistical significance of the Asian-passenger effect when, among other things, pickup location and age are controlled for, as shown in Table 8.

72. Although not for Asian or "other minority" passengers. 
these minority passengers will stiff is in all estimates on the order of 20 to 30 percentage points higher than the likelihood that white passengers will.

Hyperrational, risk-neutral drivers would discount the importance of these racialized stiffing inferences. They would care only about expected total revenue and put no independent weight on whether part of the expectation concerned stiffing fares. But a slightly more behavioral approach suggests that the stiffing disparity might powerfully complement the overall estimates of revenue shortfalls. Incidents of stiffing are likely to be particularly vivid and salient to drivers. Moreover, stiffing might produce an independent reflex of indignation ("Why should I pick up this person, who's so much more likely to insult me by stiffing me?"). These estimated tipping shortfalls and the indignation effects are the strongest evidence that revenue-based statistical discrimination may play a part in the observed reluctance of drivers to service minority passengers.

Finally, Table 8 estimates the likelihood that different passenger types will ask to be driven to distant suburbs. The idea here was to assess the inference that a cab driver would likely make about the possible cost of having to deadhead back without a return fare. In an independent analysis, we did find that white passengers asked to go to drop-off neighborhoods that were slightly more likely to have a dispatch pickup request than the drop-off neighborhoods of the average black or Hispanic passenger. ${ }^{73}$ But these drop-off disparities are not good measures of the true deadhead cost because most New Haven drop-off neighborhoods are so close to highdispatch areas.

Accordingly, Table 8 focuses instead on a dimension where the deadhead cost was more substantial. Roughly $1 \%$ of our pickup dispatches were to the more distant suburbs. A cabdriver dropping off in these suburbs thus had virtually no chance of picking up a return fare for the long ride back to New Haven. On this dimension, we found that either a rational or an irrational discriminator would infer that blacks were statistically less likely to be dropped off in the far suburbs. So, at least on this dimension, black passengers should be favored (in comparison with white passengers) for having a lower expected deadhead cost on the return trip. But on balance, deadhead inferences are likely to be second-order effects. White passengers are only about 5 percentage points more likely to ask to go to

73. The average white passenger asked to be dropped off in neighborhoods that generated $15.2 \%$ of the pickup dispatch requests, while the average African-American and Hispanic passenger asked to be dropped off in neighborhoods that generated only $11.1 \%$ and $9.1 \%$ of the pickup dispatch requests, respectively. 
distant suburbs. We doubt that this small percentage-point difference translates into a substantial difference in expected revenue. ${ }^{74}$

In the end, these estimates of racial inferences suggest that a previously unreported form of statistical discrimination may be driving some of the well-documented reluctance of cab drivers to serve minority passengers. Instead of cost-based inferences about the probability of crime, driver discrimination may in part be actuated by revenue-based inferences about the tips that will likely be earned.

TABle 9. Estimating PeRcentage ShortFall IN TIPS, AND

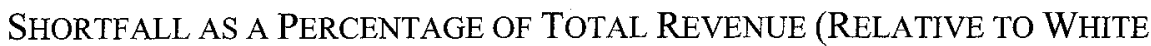
PASSENGERS), INFERABLE BY "RATIONAL DISCRIMINATORS"

\begin{tabular}{|c|c|c|}
\hline \multirow{2}{*}{ Passenger race } & \multicolumn{2}{|c|}{ Inferred percentage shortall } \\
\hline & Tip & $\%$ of total revenue \\
\hline Passenger black & $-56.50 \%$ & $-8.60 \%$ \\
\hline Passeriger hispanie & $-42.70 \%$ & $-6.40 \%$ \\
\hline Passenget Asian. & $-26.10 \%$ & $-3.90 \%$ \\
\hline Passenger otlier & $-52.00 \%$ & $-7.80 \%$ \\
\hline
\end{tabular}

Table 9 shows that rational discriminators would expect that blackpassenger tips will be $56.5 \%$ less than white-passenger tips ${ }^{75}$ and that this tipping shortfall causes the overall revenue from a black passenger to be $8.6 \%$ less than that from a white passenger. ${ }^{76}$ Analogous calculations suggest that rational discriminators would expect Hispanics to tip $42.7 \%$ less than whites, which represents a $6.4 \%$ shortfall in revenue.

Moreover, the size of the inferences that rational and irrational drivers would make about shortfalls in minority tipping are an order of magnitude larger than the inference that rational drivers might make about the heightened crime risk of serving black passengers. MetroCab informed us that there had not been more than five robberies of its drivers in the New

74. One way to get a crude handle on this magnitude is to estimate the effect of assuming that a far-suburb fare on average forced a driver to sacrifice an average-sized fare and tip. Five percent of the average fare represents only $\$ 0.52$, and this amount is almost surely inflated because it does not take into account the increased revenue to the cab driver of driving the passenger to the far suburb in the first place. On balance, drivers tend to look favorably on far-suburb trips.

75. The rational-discriminator tipping shortfall of $\$ 0.95$ divided by the predicted whitepassenger tip (evaluated at the means of the non-passenger-race variables) of $\$ 1.68$ equals $56.5 \%$.

76. The rational-discriminator tipping shortfall of $\$ 0.95$ divided by the predicted whitepassenger amount paid (evaluated at the means of the non-passenger-race variables) of $\$ 11.09$ equals $8.6 \%$. 
Haven area in any of the years leading up to our data collection. ${ }^{77}$ There are approximately 3000 fares in New Haven each day-suggesting that there is one robbery for every 219,000 fares. Even if we assume that all robberies are committed by minorities, the inferred additional cost of serving minority passengers would only be 3.8 cents per fare. ${ }^{78}$ Of course, for irrational or particularly risk-averse drivers, inferences about the additional crime costs of serving minorities might loom particularly large. But the difference between the magnitudes of a rational discriminator's inferences about tipping shortfalls and about heightened crime costs is striking.

This, then, is our core evidence that perceived minority-tipping disparities may be a cause of driver discrimination. Our data do not allow us to test whether drivers in fact make these kinds of inferences or whether such inferences translate into discriminatory behavior by cab drivers against minority passengers. But inferred disparities of this magnitude might be responsible for at least part of driver discrimination. A movement toward mandated tipping (or service compris) regulation, by reducing this perceived racial disparity in tipping, might accordingly reduce the amount of revenue-based driver discrimination.

The statistical discrimination based on perceived racial tipping differences may not be limited to the taxi industry. Indeed, Lynn's analysis of restaurants raises the possibility that statistical discrimination may be a contributing cause of some of the most publicized incidents of public accommodation discrimination in recent years. The class action lawsuits alleging racial discrimination against the African-American customers of Denny's and Cracker Barrel restaurants might be mitigated by simply moving to a service compris system. ${ }^{79}$

77. Telephone Interview with James Cox, Central Dispatch Manager, MetroCab (Feb. 21, 2003). Subsequent to our study, however, a MetroCab driver in New Haven was killed in a robbery.

78. The probability of a robbery $(0.0000046)$ multiplied by a standard measure of robbery costs (\$8416) yields an expected cost of \$0.038 per fare (in 1997 dollars). See Ian Ayres \& John J. Donohue III, Shooting Down the "More Guns, Less Crime" Hypothesis, 55 STAN. L. REv. 1193, $1281 \mathrm{n} .108$ (2003) (listing estimates for the dollar impact of crime). If we make the even more conservative assumption that all the crimes are also aggravated assaults, the additional cost of serving minority passengers increases to 11.5 cents per fare. See id. But the MetroCab official emphasized that the most serious crime committed against cab drivers in New Haven in the years leading up to this study was theft only-so inferring the additional costs of aggravated assault seems unwarranted in assessing the inferences of a rational discriminator. The subsequent murder of a cab driver in New Haven, see supra note 77, changes the result, but by less than one might think. Multiplying the probability of such a crime by a standard estimate of murder costs $(\$ 3,092,804)$ yields an expected cost of 31.4 cents per fare. See Ayres \& Donohue, supra, at 1281 n.108. Of course, drivers may also look outside New Haven in assessing the risk of harm. A single highly publicized murder, for example, could have national repercussions on risk-averse drivers.

79. See LYNN, supra note 62, at 1-8. 


\section{Alternative (NONRACIAL) HYPOTHESES}

Although the preceding regressions control for a host of nonracial variables, there are still many aspects of the transaction that we do not observe and hence cannot include in the analysis. As is often the case, the omission of right-hand-side control variables creates a possibility that the racial effects reported above may in fact be caused by nonracial factors for which we did not control. This Part outlines the major alternative hypotheses and assesses with the best data available the extent to which they qualify our two racial results.

But before proceeding to consider the particular omitted variables that may be driving the minority-driver and minority-passenger effects, we first take on more global concerns about the quality of the data reported by the cab drivers.

\section{A. Censored Data?}

It is important to remember that all the results reported above are based on surveys filled out by individual cab drivers. Misreported or censored data would substantially reduce our confidence in the results.

A weak indication of survey reliability can be found in the nonsignificance of the Survey Experience variable reported in both the Table 13 and $1 \dot{5}$ regressions. The coefficients on this variable are both very small and not statistically significant. This indicates that drivers' reported tips did not vary as they filled out more surveys. If the drivers were misreporting fares, they at least seem to have been consistently misreporting them over time.

The rejection of individual-driver random effects (as evinced by rejecting the hypothesis that the random effects variance was different from 0 ) also provides some small measure of assurance that drivers were accurately reporting fares. The random effects regressions suggest that drivers of the same race were treated similarly: If white drivers were misreporting fare data, they seem to have been doing it consistently as a group. ${ }^{80}$ The possibility that drivers explicitly colluded to misreport is unlikely for the simple reason that the drivers in the survey did not have

80. In sharp contrast, in an earlier pilot study conducted by Suzanne Perry, one of the participating drivers' surveys had markedly different (and implausible) answers. This driver reported that virtually all of his passengers failed to tip. Our impression from interacting with the participating drivers was that each took the study seriously. Most asked questions about the study, and several expressed interest in obtaining a copy of the results. One driver returned a subset of his fifty surveys, apologizing that he could not complete the set because he was going to be unable to make the lease payment on his cab that month. 
good information on the universe of drivers participating in the study. Nor did the drivers have any obvious motive to act collectively in such a manner.

Beyond misreporting of the data, there is also the possibility that drivers reported only a nonrandom sample of their total universe of fares. If drivers "censored" the transactions that they reported, we would be less sure whether our results would be robust to analysis of a broader (less censored) sample.

Unfortunately, although drivers were instructed to collect data for their "next fifty rides," there is evidence of driver censoring. To begin, we find that there are a disproportionate number of integer fares reported in the data. Fares (not including tip) are regulated in New Haven to come in twenty-five-cent increments. A full $44.4 \%$ of our observations were reported to have final meters equal to integer amounts (e.g., \$6.00). ${ }^{81}$ The length of trips, however, may not be random - so there are some benign reasons to explain why the trailing digits of the final meter would not be random. Nevertheless, the disproportionate number of integer fares-far exceeding $25 \%$ of the data-strikes us as some evidence of censoring (or at least rounding).

But even more directly, some of the drivers reported relatively few fares per day. Indeed, we find that almost half (51 out of 105) of the driverday observations included fewer than ten fares. This suggests that at least some of the time our drivers were not reporting the universe of fares encountered on a particular shift. On the other hand, in the process of arranging the distribution and collection of the survey forms it became clear that the drivers worked irregular hours. Working multiple shifts in a single day-centered on, say, morning and evening rush hours-would not be a surprising way for a driver to structure his day. ${ }^{82}$

This evidence of censoring qualifies the reliability of the foregoing results. It is possible, for example, that drivers were more likely to record

81. Of the fares, $19.0 \%$ were 25 cents over the dollar, $20.8 \%$ were 50 cents over the dollar, and only $15.9 \%$ were 75 cents over the dollar.

82. More direct evidence of this censoring can be found in our failed attempts to audit the reporting of the drivers participating in our sample. We sent a handful of student testers to take $\mathrm{cab}$ rides during the period our drivers were filling out forms. It proved to be logistically difficult to put one of the auditors into the cab of a participating driver. We ultimately were able to match testers to drivers for only ten fares. See infra notes 89 and 103 and accompanying text (discussing other aspects of the testing data). We had hoped to check whether the drivers' surveys matched with the testers' reports (same fare, same tip, etc.). But none of the ten testers' fares were reported by drivers in their survey data. Again, this strongly suggests that drivers were not reporting the full universe of fare data during the period in which they were participating in the project. However, a likely cause of censoring would seem to be insufficient time between rides for a driver to fill out the survey. Our testing regime, in which the second of two paired testers caught the same cab immediately after the first tester exited it, may have contributed to this problem. 
the results of outlier fares that made more of an impression on them, or that black drivers were more suspicious of the motives of the white male coauthor who solicited their participation in the study and sought to conceal the full magnitude of their tipping income out of, say, fear of being audited by the IRS. (That every driver reported some substantial tips, however, argues against this troubling hypothesis.) If the recorded fares are not representative of the larger universe, then the prior results may not be indicative of the broader tipping experience. However, as one of the first studies of taxicab tipping practices and one of the first quantitative studies of consumer-side discrimination, even qualified results raise important concerns about the possibility of disparate treatment (and at a minimum suggest the appropriateness of further testing).

Putting aside for the moment these important censoring concerns, we next turn to the possibility of omitted-variable problems with the two core racial results.

\section{B. Lower Tips for Minority Drivers}

Our finding of customer discrimination against minority drivers was both quite stable and robustly significant in the series of regressions in Tables 13 and 15 of the Appendix. But it is always important to consider whether omitted variables may be driving this disparate treatment result. Here we pause to consider three possibilities: individual-driver effects, disparate driver quality, and disparate customers.

Individual-Driver Effects. To begin, it is useful to assess whether what we reported as driver-race effects might instead be caused by idiosyncratic characteristics of the twelve individual drivers in the data. As an initial matter, we found that our random effects models, controlling for an increasing range of nonracial factors, rejected the presence of individualdriver effects (and after attempting to control for them nonetheless found pronounced evidence of customer discrimination). Second, if we simply calculate mean tipping percentages for each of four white and six black drivers, we find that white drivers garnered three of the four highest tipping percentages, while black drivers garnered three of the four lowest tipping percentages. ${ }^{83}$ But it is possible in nonrandom effect specifications to alternatively control for individual-driver effects by asking the regression to "cluster" the data by individual driver. ${ }^{84}$ When we rerun the regressions, clustering by individual cab drivers, we still find evidence of customer

83. One of the white drivers' average tipping percentage was particularly high (30.5\%), and one of the black drivers' average tipping percentage was particularly low $(5.9 \%)$.

84. See STATACORP, STATA USER'S GUIDE: RELEASE 6, at 256-59 (1999). 
discrimination, but the results are not as statistically significant. ${ }^{85}$ In the clustering regressions that parallel the first specification in Tables 13 and 15 , we still find that black and "other minority" drivers receive lowerpercentage tips and are more likely to be stiffed, but the results are only marginally statistically significant. ${ }^{86}$

To further explore the possibility of individual-driver effects, we also reran the most controlled specification in Table 13 controlling for native status of drivers for whom we had reliable information. In our data, all of the white drivers were native born. But of the black drivers, two were born outside the United States, two were native born, and two did not give us reliable information as to their place of birth. We found in all regressions that passenger discrimination was more pronounced against native-born black drivers than nonnative black drivers. For example, in the analogue to the most controlled specification in Table 13, tips to native black drivers were 11 percentage points less than tips to native white drivers, while tips to nonnative black drivers were only 5.1 percentage points less than tips to native white drivers. ${ }^{87}$ This suggests that controlling for the native status of drivers actually increases customer discrimination.

On balance, we still have some lingering concerns about individualdriver effects. But using a variety of reasonable approaches that alternatively control for these effects, we still find what seems to be an independent and statistically significant disparity in the tips received by minority and nonminority drivers.

Disparate Driver Quality. The driver-race disparity might alternatively be explained by potential differences in the quality of service that minority and nonminority drivers provided. If minority drivers provided systematically poorer service than white drivers, then minority drivers may have received lower tips not because of their race but because passengers may give lower tips for poorer service.

We do not have much information to respond to this theoretical possibility. The speed variable and the indicator variable for whether the

85. The clustering procedure, by its nature, generates the same coefficients as reported in Tables 13 and 15 but lets the data test whether clustering increases or decreases the level of statistical significance.

86. The Table 13 analogue suggests that the black-driver tipping-percentage result has a $p$ value of only $11.9 \%$, while the other-minority-driver result was no longer statistically significant. The Table 15 analogue suggests that the black-driver stiffing result is only significant at the $6.9 \%$ level, while the other-minority-driver result is only significant at the $9.5 \%$ level. Perry's smaller pilot study, discussed supra note 80 , was also unable to identify statistically significant customer discrimination against minority drivers.

87. Although the number of drivers is small, combining this result with our findings regarding other-race drivers (i.e., Arab and Indian) suggests the following hierarchy: White drivers receive the largest tips, followed by nonnative blacks, then native blacks, and then, finally, the "others." 
driver conversed with the passenger crudely control for two dimensions of quality. Also, other studies of tipping generally have found that variation in service quality does not explain a very large percentage of differences in the amounts that people tip. ${ }^{88}$ These studies at least suggest that the degree of racial disparity observed is not likely to have been caused by differences in quality.

We also undertook a modest amount of auditing of the drivers in our study to see if there were gross differences in the quality of service they provided. ${ }^{89}$ Based on a total of only ten audit rides with participating drivers (six rides with white drivers, four rides with black drivers), we did not find support for the hypothesis that minority drivers provided lower-quality service. Indeed, our testers subjectively rated the quality of service higher for black drivers than for white drivers (with an average rating of 4.5 out of 5 for black drivers versus an average of 3.3 for white drivers). This miniscule sample does not allow us to confidently test for quality differences. But when combined with the authors' own experience of taking numerous cabs in New Haven, we are fairly confident that the driver-race effect is not well explained by racial disparities in driver quality.

Disparate Customers. Finally, we considered whether the driver-race disparity might be caused by minority drivers serving different types of customers than nonminority drivers. Under this hypothesis, minority drivers would receive lower tips than white drivers not because customers discriminate but because minority drivers tend to provide service to lowtipping customers while nonminority drivers tend to provide service to high-tipping customers.

As discussed above, there are some structural variables that tend to push New Haven drivers toward a more random selection of customers. Both dispatchers and cab stands purport to operate on a queued basisallocating the next customer to the next driver in line. And when we restrict our analysis to either dispatched or nondispatched calls (which should be predominantly cab stand fares), we continue to find in the most controlled specification that black drivers are tipped significantly less $(9.9 \%$ for dispatched fares and $6.9 \%$ for nondispatched fares) and that this disparity is statistically significant at the $5 \%$ level. $^{90}$

88. Michael Lynn \& Michael McCall, Gratitude and Gratuity: A Meta-Analysis of Research on the Service-Tipping Relationship, 29 J. Socio-ECON. 203, 211 (2000) ("Although the average relationship between tip size and service evaluations was statistically significant in this review, it was also quite small-accounting for less than two percentage of the variability in tip percentages.").

89. See supra note 82 (discussing the driver audits).

90. The African-American-passenger coefficients in these regressions remain large and significant at the $5 \%$ level. 
But there are several dimensions on which nonrandom allocations of passengers may still occur within these subsamples. Dispatchers may, contrary to stated policy, give poorer fares to minority drivers. Drivers may engage in different strategies as to which cab stand they wait at or whether they queue for the next call from the dispatchers. Waiting at the airport may expose drivers to a different mix of passengers than waiting at the train station or at the Shubert Theater. ${ }^{91}$ And passengers may directly call a driver to schedule service. ${ }^{92}$

Table 10 shows that passenger races were not in fact randomly distributed across driver races.

\section{TABLE 10. DRIVER- AND PASSENGER-RACE FREQUENCY}

\begin{tabular}{||c|c|c|c|c|c|c||}
\hline \multirow{2}{*}{ Driver race } & \multicolumn{5}{|c|}{ Passenger race } & \multirow{2}{*}{$\begin{array}{c}\text { Number } \\
\text { of fares }\end{array}$} \\
\cline { 2 - 7 } & White & Black & Hispanic & Asian & Other & \\
\hline White & $50.7 \%$ & $25.6 \%$ & $13.0 \%$ & $9.4 \%$ & $1.3 \%$ & 446 \\
\hline Black & $44.2 \%$ & $35.1 \%$ & $12.5 \%$ & $7.1 \%$ & $1.0 \%$ & 504 \\
\hline Other & $34.3 \%$ & $28.3 \%$ & $17.2 \%$ & $17.2 \%$ & $3.0 \%$ & 99 \\
\hline Number of fares & 483 & 319 & 138 & 95 & 14 & 1049 \\
\hline
\end{tabular}

Note: Pearson test of independence: $\chi^{2}(8)=25.9082 ; \operatorname{Pr}=.001$.

Black drivers were more likely than white drivers to have black passengers $(35.1 \%$ versus $25.6 \%)$, and white drivers were more likely than black drivers to have white passengers (50.7\% versus $44.2 \%)$. But drivers of each race were still exposed to substantial numbers of black, Hispanic, and white customers (which again aids in testing for the existence of customer discrimination) ${ }^{93}$ We found, for example, that a Pearson chi-squared test of statistical independence rejected the hypothesis that black and white drivers have the same passenger racial composition $(p=.01)$. But we found no

91. Steve Salop helpfully suggested that we reanalyze the data to try to better control for more aggregated driver strategies over the course of a shift. In this more aggregated analysis, we would have tested whether driver-race disparities persist at the shift level when we take into account that waiting at the airport takes longer but is expected to generate a larger fare. However, the problem of incomplete shift data, discussed supra Section V.A, unfortunately precludes us from analyzing shift data in a systematic way.

92. But this last possibility may still be an example of customer discrimination, if customers systematically prefer to schedule with white drivers.

93. There was a substantially higher percentage of blacks and Asians among our passengers (30.4\% and $9.1 \%$, respectively) than is found in the New Haven County population $(11.3 \%$ and $2.3 \%$, respectively) - and there was a substantially lower percentage of whites ( $46 \%$ in our sample versus $79.4 \%$ in the general population). See Census Bureau, supra note 36 . 
statistical difference in the average fare of black, white, or "other minority" drivers.

One way to reduce the risks that the driver-race disparity might be driven by nonrandom allocation of passengers is to see whether the result persists in subsets of the data that have even better indicia of random allocation. We pursued this strategy by looking at a subset of the nondispatched fares where the pickup occurred at the New Haven train station. These 319 observations ( 242 of which are preserved by the most controlled specification) have fairly strong indicia of random assignment, because the train station cab stand uses a strict first-in-line principle and neither drivers nor passengers have much discretion to pass on a fare. Restricting our attention to this subsample, we continue to find in our most controlled specification that African-American drivers are tipped less than white drivers $(7.2 \%)$ - and this disparity is still statistically significant at the $7 \%$ level. $^{94}$

While the evidence of nonrandomized allocations makes it more difficult to test for customer discrimination, our regressions controlled for a host of nonracial differences and still found robust statistical evidence that minority drivers were tipped less, even after controlling for minority drivers' heightened chance of serving minority customers and even after controlling for customers' nonrandom allocation of neighborhoods. Accordingly, the disparate customer hypothesis does not, in the end, present a strong challenge to our earlier results.

\section{Lower Tips by Minority Passengers}

It is superficially inviting to conclude from our earlier results that the minority status of either the driver or the passenger causes the expected tipping percentage to be lower. But these two racial effects stand on very different theoretical and empirical footings. As a theoretical matter, it is straightforward in randomized data to test whether one person's race influenced the decisions of another person-for example, whether $X$ refused to sell to $Y$ because $Y$ was black. But it is much harder to test whether the behavior of a decisionmaker herself was affected by the decisionmaker's own race. And given the real limits on our knowledge about passengers' socioeconomic status, we have instead focused in Part IV on the racial inferences that drivers (who have similarly imperfect information) might make.

94. The African-American-passenger coefficient also remains large (7.4\%) and significant at the $1 \%$ level. 
Nonetheless, other tipping studies suggest that even if we could control for a host of socioeconomic variables, African-American passenger status would likely remain associated with lower tip amounts. An independent literature exists examining whether customer race affects tipping size, particularly (but not exclusively) in restaurants. The least persuasive studies merely survey service providers about their general impressions. For example, a Houston survey of fifty-four waiters and waitresses found that ninety-four percent of them classified African Americans as poor tippers, whereas none of them classified whites as poor tippers. ${ }^{95}$

There are also numerous recorded racialized incidents concerning server perceptions of African Americans as being poor tippers. ${ }^{96}$ For example,

On October 23, 1999, Charles Thompson and Theresa White went out for dinner at Thai Toni Restaurant in Miami Beach, Florida. When they got their bill, they found that a 15 percent gratuity had been added even though no similar charges were added to the bill of a nearby couple. Mr. Thompson asked the restaurant['s] owner/manager for an explanation and was told: "You black people don't tip well.","7

The Miami-Dade Board of County Commissioners reacted by passing an ordinance forbidding discriminatory tipping practices in eating establishments. ${ }^{98}$

More authoritative studies take one of two forms. Some of the studies, like ours, have restaurant servers record information about their

95. Michael Lynn, Servers' Perceptions of Who Are Good and Poor Tippers 2 (2000) (unpublished manuscript, on file with authors).

96. For example, an anonymous posting from an online discussion board expressed the following perception:

When I worked at T.G.I[.] Fridays, I noticed that many tips from African

American parties were not based upon a percentage of the check, but were typically an arbitrary amount and were usually in the two-to-five-dollar range. This is not to say that all African Americans left small tips, but a significant number did.

Posting of Jim to http://www.tipping.org/discus4/messages/9/125.html (May 4, 2002 7:52 EST).

97. Michael Lynn \& Clorice Thomas-Haysbert, Ethnic Differences in Tipping: Evidence, Explanations, and Implications 3 (2003) (unpublished manuscript, on file with authors).

98. This single episode brought down a firestorm of protest. "The NAACP organized a protest outside the restaurant; the Greater Miami Convention and Visitors Bureau removed the restaurant from its membership list; [and] the Florida Attorney General charged the restaurant with violating the state's Deceptive and Unfair Trade Practices Act . . . ." Id.; see also Ruben Castaneda, Restaurant Sued over Tip Dispute; 15\% Was Added to Lunch Bill for Black Women, WASH. POST, Apr. 13, 2000, at B3 (describing this incident in the context of a similar one in Maryland). 
customers. $^{99}$ Other studies are based on interviews of customers as they depart restaurants. ${ }^{100}$ Michael Lynn and Clorice Thomas-Haysbert conducted something akin to a meta-analysis in which they pooled the data from five different studies of restaurant tipping in Houston. ${ }^{101}$ The authors found that African-American customers were expected to tip 3.59 percentage points less than white customers $(p<.0001){ }^{102}$

While the restaurant studies are suggestive, they too may be infected by the problem of omitted-variable bias. Next we examine two ways in which our prior tipping regressions are incomplete and may misattribute effects to passenger race that are not really there.

Service, Not Passenger Race. If drivers systematically offer poorer service to minority customers, then the regressions may mistakenly suggest that African Americans and Hispanics tend to tip less at a given level of service. Instead, it may just be that passengers of all races tend to tip less for poor service and that drivers disproportionately give poor service to minority passengers. This alternative hypothesis is a concern because we have only very weak controls for driver quality (chiefly speed and conversation). ${ }^{103}$

There are, however, several different forms the poor service hypothesis might take, depending on the scope of the poor treatment that might actuate lower tips. For example, minority passengers might tip less because (1) the current driver, (2) a prior driver, or (3) a prior retailer provided poorer service to the minority passengers (or their families or friends). Indeed, it is

99. Michael Lynn et al., Reach Out and Touch Your Customers, 39 CORNELL HOTEL \& RESTAURANT ADMIN. Q., June 1998, at 60; Michael Lynn, Tipping: A Reward for Server Effort? (2000) (unpublished manuscript, on file with authors).

100. Michael Lynn \& Jeffrey Graves, Tipping: An Incentive/Reward for Service?, 20 HosPITALITY RES. J. 1 (1996); Connie Mok \& Sebastian Hansen, A Study of Factors Affecting Tip Size in Restaurants, 3 J. RESTAURANT \& FOODSERVICE MARKETING 49 (1999).

101. Lynn \& Thomas-Haysbert, supra note 97, at 13-14. The studies pooled include those listed supra notes $99-100$.

102. Lynn \& Thomas-Haysbert, supra note 97, at 16-17. Perry's pilot study, discussed supra note 80 , also found statistically significant shortfalls in the percentage tipped by African Americans relative to whites.

103. Although we hypothesized that greater speed and having a conversation would generally be viewed positively, too much of either would obviously ruin a ride. In fact, neither variable had a significant impact on tipping percentage or stiffing, as shown in Tables 13 and 15 of the Appendix.

Our limited attempt at using testers to audit the drivers themselves (which yielded only ten observations) provides a smidgen of information related to the service issue. Our testers included a pair of men, one white and one African American, and a pair of women, one white and one Indian American (Asian subcontinent). The testing regime was structured so that both members of each pair took rides with the same drivers. One item on the testers' survey was "quality of service." We found that our minority testers actually rated the quality of service slightly higher than white testers (3.98 on a 5-point scale for five rides by minority passengers versus 3.56 for five rides by nonminority passengers). In addition, the testers' relative rankings of driver quality were identical. Hence, the hypothesis that minority passengers might tip less because they receive poorer service does not find support in this handful of observations. 
theoretically possible that minority passengers and drivers are caught in a mutually reinforcing, unhappy equilibrium in which minority passengers give little because they are generally exposed to poor retail treatment, while drivers generally provide poor treatment because they expect a poor tip.

Class, Not Passenger Race. Second, as discussed above, the tendency of nonminority passengers to tip more may be driven by socioeconomic class differences. Possibly, rich people tip more, not white people. But our regression does not pick up this impact because, again, we have only very poor correlates with class (passenger dress and pickup and drop-off locations).

There is another piece of evidence that could be construed to suggest that poverty might be driving poor tipping. If we break down the stiffing rates by fare type, we find that relatively few whites or blacks are willing to stiff when the fare ends up being 75 cents over the dollar. But when the fare ends up being 25 cents over the dollar, African Americans show a much greater propensity (31 times greater than whites) to stiff drivers. This is consistent with the hypothesis that poverty is disproportionately important to African-American passengers: When more money ( 75 cents) is at stake, African Americans are more willing to stiff.

TABLE 11. MEAN STIFFING BY PASSENGER RACE AND FARE TYPE

\begin{tabular}{|c|c|c|c|c|c|c|c|c|}
\hline Race & $\begin{array}{l}\text { Integer } \\
\text { fare }\end{array}$ & $\begin{array}{c}\text { Race/ } \\
\text { white } \\
\text { disparity } \\
\text { ratios }\end{array}$ & $\begin{array}{c}\$ 0.25 \\
\text { over } \\
\text { the } \\
\text { dollar }\end{array}$ & $\begin{array}{c}\text { Racel } \\
\text { white } \\
\text { disparity } \\
\text { ratios }\end{array}$ & $\begin{array}{c}\$ 0.50 \\
\text { over } \\
\text { the } \\
\text { dollar }\end{array}$ & $\begin{array}{c}\text { Racef } \\
\text { white } \\
\text { disparity } \\
\text { ratios }\end{array}$ & $\begin{array}{l}\$ 0.75 \\
\text { over the } \\
\text { dollar }\end{array}$ & $\begin{array}{c}\text { Racel } \\
\text { white } \\
\text { disparity } \\
\text { ratios }\end{array}$ \\
\hline White & $22.1 \%$ & - & $1.0 \%$ & - & $3.6 \%$ & - & $5.1 \%$ & - \\
\hline Black & $61.5 \%$ & 2.78 & $32.7 \%$ & 31.42 & $23.3 \%$ & 6.42 & $6.9 \%$ & 1.36 \\
\hline Hispanic & $50.7 \%$ & 2.29 & $13.6 \%$ & 13.09 & $20.8 \%$ & 5.73 & $6.3 \%$ & 1.23 \\
\hline Asian & $26.2 \%$ & 1.18 & $10.7 \%$ & 10.29 & $0.0 \%$ & 0.00 & $11.1 \%$ & 2.19 \\
\hline Other & $50.0 \%$ & 2.26 & $0.0 \%$ & 0.00 & $33.3 \%$ & 9.17 & $0.0 \%$ & 0.00 \\
\hline
\end{tabular}

Fortunately, a new study by Lynn has good controls for both income and service. The study consists of a national telephone survey he conducted eliciting information from approximately 900 consumers on their tipping behavior with regard to nine different types of service providers-including taxi drivers. ${ }^{104}$ The respondents were asked not only their race, sex, and age, but also their income (in ten ordered categories) and education (in seven ordered categories). The survey additionally controlled for service quality

104. Michael Lynn, Black-White Differences in Tipping of Various Service Providers (2003) (unpublished manuscript, on file with authors). 
in the way the tipping question was framed. For example, with regard to cab tipping, respondents were asked, "If you received good service from [a cab or limousine driver] would you tip them a percent of the total cost of the service, tip them a flat amount or not give them a tip?" 105 Respondents who said they would leave a percentage or flat tip were then asked, "What amount?" 106 Lynn found that African-American respondents were 11\% more likely than white respondents to say that they would stiff a cab or limo driver $(p<.03)$. There was no significant racial difference, among those who said they would leave a tip, in the propensity to leave a flat amount and no significant racial difference in the amount of flat tips. But among percentage tippers, Lynn, controlling for income, found that AfricanAmerican respondents were likely to report tipping 1.99 percentage points less than white respondents. However, this result falls slightly short of statistical significance $(p=.14)$.

Lynn did not aggregate the three types of responses (stiff, percentage, and flat) to get an overall assessment of racial disparities. But controlling for service and income does seem generally to narrow the passenger-race disparities in propensity to stiff and in average tipping percentage as compared with our previous findings. ${ }^{107}$

History. A final explanation of lower minority tipping resuscitates the brief history discussed in Part I. At one time, accepting tips was seen as a symbol of the recipient's degradation. Minorities may at one time have been unwilling to tip, ${ }^{108}$ not because they were disproportionately poor or

105. Id. at 5 (internal quotation marks omitted).

106. Id. at 6 (internal quotation marks omitted).

107. Lynn has also conducted a survey that asks, "Thinking about tipping overall, not your own practices, how much is it customary for people in the United States to tip waiters and waitresses?" LYNN, supra note 62, at 11 (internal quotation marks omitted). Lynn finds marked differences in the ways that blacks and whites respond:

[B]lacks are more likely than whites to say that:

they do not know the customary restaurant-tip amount in the United States (12.1

percent for blacks[] and 2.4 percent for whites);

the customary restaurant-tip amount is less than 15 percent of the bill (28.3

[percent] for blacks and 17.5 percent for whites); and

the customary restaurant-tip amount is a dollar amount rather than a percentage of

the bill ( 15.2 percent for blacks and 3.3 percent for whites).

$I d$. at 12 . These differences remain statistically significant after controlling for the respondent's income, sex, age, education, household size, and residence in a metropolitan area. Lynn interprets these results as suggesting that African Americans are not familiar with the U.S. norm of tipping $15 \%$ to $20 \%$. But an alternative interpretation is that African Americans are not familiar with the white tipping norm and that whites are not familiar with the African-American tipping norm.

108. A recent study conducted by the Chronicle of Philanthropy shows that the tendency of African Americans to tip less is not symptomatic of a general lack of generosity in other arenas. In fact, this study found that African Americans give to charity a higher proportion of their discretionary income than whites $(8.6 \%$ versus $6.4 \%)$. Michael Anft \& Harvy Lipman, Special Report: How Americans Give, CHRON. PHILANTHROPY, May 1, 2003, at 6, 8. The study analyzed the $18 \%$ of the U.S. population who earn $\$ 50,000$ or more and itemize tax deductions. Id. at 6 . These individuals donated about $80 \%$ of the total $\$ 122$ billion donated in 1997 . Id. at 7 . Of people 
because they were receiving poorer treatment but because they did not want to participate in a practice that had been so often framed as a token of their own inferiority. ${ }^{109}$ Of course, this degradation conception of tipping may have long passed. But both minority and nonminority consumers today may still be affected by this now-withered perception-because one generation passes its tipping practices on to the next. ${ }^{110}$

Stepping back, we are most concerned about the possibility that drivers nonrandomly censored the data in ways that might undermine the reliability of our primary results. This censoring effect by itself should qualify anyone's reading of the data, and it underscores the preliminary nature of the study. In contrast, we are less concerned with the various omittedvariable concerns discussed with regard to the driver-race and passengerrace effects. The evidence of customer discrimination against minority drivers is relatively stable and robustly significant. The evidence that African-American and Hispanic passengers tip less is slightly less stable and declines in size as better controls for class (captured by pickup and drop-off locations) are added. But even after taking out the class component (to the extent our data permit), there seems to be an independent and robustly significant passenger-race disparity in tipping (particularly with respect to stiffing propensities).

\section{WHY ARE CONSUMERS DISCRIMINATING?}

Statistically identifying the cause of disparate treatment is usually a daunting task. ${ }^{111}$ And our survey of cab drivers seems particularly ill suited to uncover the wellsprings of customer motivation. Nonetheless, this Part tries to tease out of the data a few statistical intimations that are at least suggestive of the extent to which the disparate treatment is conscious.

Our first inclination was to be skeptical that conscious discrimination could be playing much of a role in the overall shortfall for minority drivers. Is it really possible that many passengers would overtly tip a lower percentage because the driver was a minority? But the racial disparity in the

with incomes of $\$ 50,000$ or more, African Americans donated an average of $\$ 1204$ to charity, while whites donated only an average of $\$ 1072$. This racial disparity is particularly pronounced with regard to religious giving: African Americans donated $7.7 \%$ of their discretionary income to churches, while whites donated only $4.8 \%$. In contrast, among people eaming more than $\$ 50,000$ who itemized, whites donated $1.6 \%$ of their discretionary income to nonreligious recipients, while African Americans donated only $0.9 \%$. Id . at 8 .

109. As reported above in Table $5,39.2 \%$ of African-American passengers left no tip, as compared with just $10.6 \%$ of white passengers.

110. Recall that children generally know when and how much their parents tip. See supra notes $12-13$ and accompanying text.

111. See, e.g., AYRES, supra note 1, at 54 (attempting to statistically identify the cause of disparate treatment in new car sales). 
rates of stiffing gives one pause. Recall from Table 3 that black drivers were $80 \%$ more likely to be stiffed than white drivers $(28.3 \%$ versus $15.7 \%$ ). Table 15 of the Appendix shows that this disparity was sustained as we controlled for more variables. The disparity in the stiffing rate suggests that stiffing is not just caused by a hard-wired set of passengers who never tip. Rather, passengers tend to sometimes make a conscious decision to leave no tip. This does not mean that passengers were consciously stiffing based upon the cab driver's race, but it does suggest that conscious decisionmaking of some kind was at work.

In contrast, there is another part of the data that resonates with the notion of unconscious thought processes. People deciding how much to tip often choose to either round up or round down to the dollar nearest their preferred total (including tip). ${ }^{112}$ If we use the average passenger-race tipping percentages (from Table 4) to make predictions about passengers' preferred tipping percentages, it is possible to identify those instances in which the tip given was just sufficient to round the total payment up or down to the nearest dollar. Table 12 divides the tipping data into instances where passengers rounded the total amount to the integer nearest this target amount.

\section{TABLE 12. DISTRIBUTION OF ROUNDED AND NONROUNDED TOTAL AMOUNTS PAID}

\begin{tabular}{|c|c|c|}
\hline & $\begin{array}{c}\text { Number of } \\
\text { fares }\end{array}$ & $\begin{array}{l}\text { Percentage of } \\
\text { total number } \\
\text { of fares }\end{array}$ \\
\hline Total rounded to nearest integer & 580 & $54.8 \%$ \\
\hline Rounded down to nearest integer: & 286 & $27.0 \%$ \\
\hline 7. Rounded up to nearest niteger & 294 & $27.8 \%$ \\
\hline Rounded to another integer: & 176 & $16.6 \%$ \\
\hline Nentominded & 303 & $28.6 \%$ \\
\hline Total & 1059 & $100.0 \%$ \\
\hline
\end{tabular}

We find that $54.8 \%$ of the tips in the data set were rounded by the passenger to the dollar nearest our prediction of the passenger's preferred tipping percentage. These rounded observations, to our minds, are prime

112. Tipping one's preferred percentage is harder to accomplish in cash transactions than in credit card transactions (where the customer may have an easier time filling in a nonrounded total amount). Accordingly, we would expect the rounding phenomenon to be more important with regard to cash tips in a taxi than with regard to credit card tips in a restaurant. 
candidates for unconscious discrimination. Imagine the following scenario: Just before your cab arrives the fare clicks over to $\$ 7$. Think fast. Do you leave $\$ 8$ or $\$ 9$ ? We suspect that passengers are often called on to make a quick decision about whether to round up or down. Even people who think that they are hard-wired percentage tippers may find that unconscious factors influence this rounding decision. Just as people who confront the Implicit Association Test sorting game often can't help but treat blacks and whites differently, ${ }^{113}$ people who confront the dichotomous rounding game may have trouble purging the influence of race.

In fact, when we analyze the rounded observations, we find a bit of evidence to support this form of unconscious discrimination. Overall, passengers were $6 \%$ more likely to round up rather than round down with a white driver than with a black driver. ${ }^{114}$

Finally, we tried to decompose the total black/white driver-tipping disparity of 7.7 percentage points (from Table 2) into two component parts: a stiffing disparity and a rounding disparity. ${ }^{115}$ We find that $27.2 \%$ of the overall disparity comes from the propensity to stiff minority drivers and that $35.5 \%$ of the overall racial disparity comes from different propensities to round when paired with a minority driver.

This decomposition suggests that both unconscious and conscious motivations may play a role in consumer discrimination. But we should again emphasize the weakness of these conclusions. We are pushing the data to the limits of their competence, and while the evidence of disparities in stiffing is quite robust and by itself explains a substantial portion of customer discrimination, the evidence of disparities in rounding is much more tentative and turns, among other things, on our particular method of predicting individual customers' preferred tipping percentages.

\section{NORMATIVE IMPLICATIONS}

Before examining two primary normative implications of our results, it is worth pausing to note that the finding of lower tips for minority drivers raises interesting issues about the scope of our civil rights laws. Does the

113. AYRES, supra note 1 , at 419-20.

114. But somewhat surprisingly, this overall effect is driven by the behavior of minority passengers. Minority passengers were more likely to round up when paired with a white driver than when paired with a minority driver. But white passengers were less likely to round up with white drivers than with black drivers. However, in an alternative form of this analysis using regression-based predictions, other passenger races, including black passengers, were also less likely to round up with white drivers.

115. The rounding disparity is calculated as the weighted difference of the black and white rounded tipping-percentage averages. The stiffing disparity is calculated as the (generally) increased probability of a black-driver stiff multiplied by the white-passenger tipping-percentage average over nonrounded fares. (Note that stiffs are defined not to be rounded fares.) 
evidence of customer discrimination against minority drivers suggest a violation of $\S 1981$ ? Section 1981 is a broad prohibition against race discrimination in contracting. ${ }^{116}$ But we have not been able to find a case challenging discrimination by buyers. Indeed, Jones v. Alfred H. Mayer Co. famously found that the goal of the 1866 Civil Rights Act was to ensure that "a dollar in the hands of a Negro will purchase the same thing as a dollar in the hands of a white man." 117 The focus is on protecting minority buyers, not minority sellers.

And even if the statute's broad language were read to regulate buyer behavior, it is far from clear that a passenger's tipping decision concerns discrimination in the terms of a contract. Even though the law has increasingly treated tips as wages for tax purposes, ${ }^{118}$ disparate treatment in tipping does not concern a formal term of agreement and thus might not impair the right of minority drivers to make and enforce contracts. ${ }^{119}$

But whether or not these legal obstacles could be cleared, there are abundant logistical problems that would preclude the use of $\S 1981$ or any other civil rights statute to discourage passenger discrimination. The difficulty and cost of proving that an individual passenger tipped less because of the driver's race would block even the most subsidized litigation. Our findings of passenger discrimination illuminate interesting issues of civil rights law, but they do not suggest (to our minds) a viable new form of litigation.

That said, we believe that there are two primary normative implications of the foregoing analysis. First, the government should be careful in its tax laws not to add insult to injury by directly or indirectly attributing phantom tipping income to minority drivers. ${ }^{120}$ The second and more important implication is a tentative proposal to raise taxi fares by $15 \%$ and to require "Tip Included" decals to be prominently displayed in all cabs. At a minimum, this Essay has identified two new rationales for such mandatedtipping regulation.

\section{A. Adding Insult to Injury?}

There are several ways in which the disadvantages to minority drivers (and, more generally, minority employees) resulting from consumer

1i6. See 42 U.S.C. $\S 1981$ (2000) ("All persons ... shall have the same right ... to make and enforce contracts ... as is enjoyed by white citizens ....").

117. 392 U.S. 409,443 (1968).

118. SEGRAVE, supra note 8 , at 123.

119. See Patterson v. McLean Credit Union, 491 U.S. 164 (1989) (limiting the $\S 1981$ cause of action to discrimination in making and enforcing contracts as opposed to discrimination in performance).

120. Bruce Ackerman pointed this implication out to us. 
discrimination could be exacerbated by methods of estimating tipping income for tax purposes. ${ }^{121}$ For example, a business establishment enrolled in the Tip Rate Determination Agreement (TRDA) is required to work with the IRS to determine a baseline tip rate for its employees. ${ }^{122}$ If this imputed tipping income is based on the overall average-which is likely to be greater than the minority average-minority employees will be taxed on money they did not earn; put another way, minority drivers will be forced to pay taxes at an effectively higher rate than their white counterparts. Furthermore, "TRDA provides that if employees fail to report at or above the determined rate, the employer will provide the names of those employees, their social security numbers, job classification, sales, hours worked, and amount of tips reported." 223 Hence, a minority employee conscientiously reporting tip income could be threatened with a higher risk of audit and job loss.

An alternative to the TRDA is the Tip Reporting Alternative Commitment (TRAC). Although TRAC does not require the determination of a baseline tipping rate-instead requiring methods for directly reporting tip income-it does provide that "if the employees of an establishment collectively underreport their tip income, tip examinations may occur but only for those employees that underreport." 124 Hence, in cases where the IRS regards employees as collectively underreporting, minority drivers are likely to bear an unfair portion of the blame and therefore again are more likely to be audited or lose their jobs.

Presently, TRDA and TRAC are available to the food and beverage, hairstyling, and gambling industries, so that in these businesses in particular minority employees might be shouldering the multiplied burdens of lower tipping income, higher tax rates, and greater possibility of audits and job loss. According to the IRS, "Plans are underway to extend this program to all industries where tipping is customary." 125 An immediate implication of the results presented in this Essay is that, unless adjustments are made to take into account lower minority-tipping incomes, programs such as TRDA and TRAC may compound the problem of consumer discrimination.

121. It might be questioned why literal gratuities count as income at all, because they more closely resemble gifts than contracted-for wages. Nonetheless, courts universally treat tips as part of wages for a variety of different legal purposes. For a history of the treatment of tips as wages, see SegRave, supra note 8, at 12. See also SAMUEL ESTRICHER \& JONATHAN R. NASH, THE LAW AND ECONOMICS OF TIPPING: THE LABORER'S PERSPECTIVE (Am. Law \& Econ. Ass'n Annual Meetings, No. 54, 2004), available at http://law.bepress.com/alea/14th/art54 (discussing the tax implications of tipping).

122. IRS, PUBL'N 3144, TIPS ON TIPS: A GUIDE TO TIP INCOME REPORTING FOR EMPLOYERS IN BUSINESSES WHERE TIP INCOME IS CUSTOMARY 4 (2000).

123. Id. at 5 .

124. Id.

125. Id. at 3 . 
Furthermore, studies of consumer discrimination are necessary for those industries in which TRDA and TRAC are already in use, to determine whether minority workers do in fact earn systematically lower tipping incomes and are therefore disadvantaged by the programs. ${ }^{126}$

Apart from programs estimating tip income, minority drivers or employees may be unfairly exposed to audits and penalties simply because their reported tipping incomes may appear suspiciously low. According to the IRS, failure to report tips can result in "a penalty equal to $50 \%$ of the social security and Medicare taxes or railroad retirement tax [owed] on the unreported tips"127 (as well as a "negligence penalty of $20 \%$ of the additional income tax, plus interest" ${ }^{128}$ ). Hence minority drivers may be unfairly subject to additional penalties as a result of consumer discrimination.

\section{B. Service Compris}

While our "phantom income" concern is analytically sound, we are agnostic about its empirical importance. Driver noncompliance with tax laws may be so rife that it is hard to tell whether minority drivers are given less room to cheat on their reporting of income or would be subject to a higher chance of audit on conscientiously reported income. Our second proposal is more important, but more controversial.

The central idea is that prohibiting all tipping would likely reduce two types of disparate racial treatment: It would directly stop passengers from discriminating against minority drivers, and it might reduce some driver discrimination against minority passengers. This second point will be more fully elaborated in just a moment. But first, a word about implementation.

\section{Implementation}

It would be possible for the law to directly prohibit tipping. Indeed, anti-tipping statutes of just this kind were passed at the beginning of the twentieth century by a handful of states. ${ }^{129}$ But enforcement of a strict prohibition would be impossible. Who is to know if a passenger slips a driver a few extra dollars before exiting the cab? And why would police

126. A further possible problem that might result from the imputation of tipping income is in the withholding of wages for tax purposes. If a uniform percentage of income is withheld for all employees on the basis of an assumed baseline tipping rate, that sum will be disproportionately large for minority employees.

127. IRS, PUBL'N 531, REPORTING TIP INCOME 4 (2004).

128. IRS, PUBL'N 3148 , TIPS ON TIPS: A GUIDE TO TIP INCOME REPORTING FOR EMPLOYEES WHO RECEIVE TIP INCOME 4 (2000).

129. See Cook, supra note 18. 
have an incentive to investigate or prosecute such small-potatoes infractions? Moreover, we imagine that the prohibition would incense many passengers ("What right does the government have to say that I can't tip?") and would incite noncompliance.

Instead, we tentatively propose that cab commissions simultaneously increase the metered price by $15 \%$ and require cabs to prominently display "Tip Included" decals. Enforcement of the decal requirement is much more feasible, because decals are rather durable and because enforcers don't need to observe the private interactions between drivers and passengers-they just need to check off whether a decal is in place when they are already inspecting the cab.

Regulation of this kind, known as service compris, is also likely to motivate a much higher degree of passenger compliance. Passengers are likely to know that the fare has been increased by $15 \%$ and will not feel an obligation to double pay. To be sure, in many countries there has arisen a norm of paying a small tip in addition to the service compris amount added to one's check. ${ }^{130} \mathrm{~A}$ similar add-on norm might also develop under our proposed system.

But the key point here is that amounts added on are likely to be a lot less than the $16 \%$ mean tip in our study. If the most generous passengers add on at most $5 \%$ under a service compris regime, there simply will not be enough room for either of the race effects uncovered above. Both (1) the amount of customer discrimination against minority drivers and (2) the shortfall in tipping by African-American and Hispanic passengers are likely to decline.

\section{Reducing Driver Discrimination}

The effect of service compris regulation on customer discrimination against minority drivers would be straightforward. ${ }^{131}$ Anything that reduces

130. See Embassy of Fr., Tipping in France, http://www.info-france-usa.org/visitingfrance/ tipping.asp (last updated Jan. 18, 2002) (noting that in service compris establishments, "it is customary to leave small change unless you are dissatisfied").

131. Customer race discrimination may be an important impediment to the growth of minority-owned business. Indeed, two of us have argued that evidence of downstream discrimination by customers provides a constitutional basis for government affirmative action. Ian Ayres \& Fredrick E. Vars, When Does Private Discrimination Justify Public Affirmative Action?, 98 COLUM. L. REV. 1577, 1614-15 (1998). Courts and commentators appreciate how upstream discrimination (that is, discrimination by a minority firm's suppliers) can impede a firm's ability to compete, but they often fail to consider how downstream discrimination by one's customers can also create racialized barriers to entry. Jennifer Lee makes this point with respect to downstream discrimination by black customers against black-owned firms: "[B]lack merchants often charge higher retail prices because their suppliers charge them higher wholesale prices than they do other business owners. ... Black merchants, on the other hand, complain that black customers refuse to patronize their own, opting instead to buy from neighboring Jewish and Korean merchants." Lee, 
customer discretion with regard to tipping should predictably reduce the opportunity for customers to discriminate.

But reduced tipping discretion may also reduce a second type of race discrimination-discrimination by drivers against minority customers. As discussed in Part IV, if drivers expect to be tipped less by minority passengers, they may refuse to pick up these customers in favor of bettertipping white customers.

Lynn has previously diagnosed the possibility that low minority tips lead to service discrimination, arguing that "if Blacks do tip less than Whites, then managers should try to change their Black customers' tipping behavior and/or should closely monitor their tipped employees' treatment of Black customers. Otherwise, their tipped employees are likely to deliver inferior service to Black customers whom they believe are poor tippers." 132 More recently, Lynn has called for a multimedia advertising campaign aimed at informing African Americans of the 15\%-to-20\% tipping norm (and ridiculing people who tip less). ${ }^{133}$ Our proposal inverts his proposed intervention. Instead of encouraging minorities to tip more, we propose a (much more feasible) regime to induce nonminorities to tip less. ${ }^{134} \mathrm{We}$ propose to eliminate (or at least to substantially decrease) discretionary tipping across the board.

While it might at the moment seem that the practice of tipping in certain service industries is too embedded in American norms to be displaced, ${ }^{135}$ it is useful to remember our earlier discussion of the strong antipathy that many Americans had for tipping less than 100 years ago. "The Anti-Tipping Society of America, an alliance of 100,000 traveling salesmen, managed to have tipping abolished in seven states from 1905 to 1919 . ..." ${ }^{136}$ As late as 1946, Life magazine concluded that "tipping was a

supra note 4, at 93 (emphasis added) (citation omitted). Customer discrimination of the kind uncovered in this Essay may therefore also be relevant to government attempts-via affirmative action in procurement - to counteract the impact of private discrimination. See Ayres \& Vars, supra, at 1612.

132. Lynn, supra note 104 , at 4.

133. LYNN, supra note 62, at 22.

134. Indeed, one of the surprising possible implications of our research is that the enhanced restaurant tipping norm for progressive patrons - which has gradually developed over the last fifty years, ratcheting up the expected tipping percentage for servers from $10 \%$ to $15 \%$ and then from $15 \%$ to $20 \%$ may have actually had the nonprogressive effect of enhancing server discrimination against minority customers.

135. That Americans only tip certain, apparently arbitrary, categories of service workers itself suggests that we are not hard-wired tippers. For example, we tip the shoeshine person but not the salesperson who helped us pick out the shoes.

136. Cook, supra note 18. Anti-tipping statutes were repealed in South Carolina in 1922, Arkansas in 1925, Tennessee in 1925, and Mississippi in 1926. Herman Steutzer, Jr., Note, 17 CORNELl L.Q. 183, 188 n.41 (1931); cf. Ex parte Farb, 174 P. 320 (Cal. 1918) (holding that an anti-tipping statute violated the Due Process Clause of the U.S. Constitution and the freedom of contract provision of the California Constitution); Dunahoo v. Huber, 171 N.W. 123, 123 (Iowa 
national nuisance and as such should be eliminated." 137 At that time, fully $69.7 \%$ of the general public would have preferred that tipping be eliminated, provided that service workers were provided with fair wages. ${ }^{138}$ All this is to say that a social practice that today seems an inevitable or inherent part of our economy may not seem so inevitable if we look slightly into the past (or to other parts of the world).

\section{Countervailing Effects}

This Essay has identified two new reasons that militate in favor of mandated-tipping regulation. But showing that service compris might reduce two different types of disparate racial treatment does not prove that this intervention would be on balance beneficial. In this Subsection, we briefly consider two countervailing effects that militate against our proposal.

First is a countervailing civil rights effect. Mandating that a tip be included in the fare could make taxis too expensive for poor people (who are themselves disproportionately people of color). The current tipping norm may provide less-well-off citizens the opportunity to purchase transportation services at an effectively discounted price if they choose not to tip the driver. A service compris regime may reduce two forms of disparate treatment, but it may simultaneously also create a disparate impact on minorities. Hence, there may be a disparate impact/disparate treatment tradeoff: African Americans may find it easier to hail a cab under service compris but be less able to afford the offered ride. ${ }^{139}$

Traditionally, disparate treatment violations have been seen as the more central civil rights concern. ${ }^{140}$ How we as a society choose to manage this tradeoff may also turn in part on whether we view a tip as a discretionary gift to a driver or as an earned portion of driver compensation. If the latter, it is hard to be too concerned about retaining a system that facilitates two

1919) (holding that an anti-tipping statute violated the state privileges and immunities clause because there was no reasonable ground for allowing employers to accept tips when employees were prohibited from accepting tips while "engaged in the same occupation"). (1947).

137. Leo P. Crespi, The Implications of Tipping in America, 11 PUB. OPINION Q. 424, 424

138. Id. at 426.

139. Another countervailing civil rights effect is theoretically possible. Stripped of the opportunity to discriminate against black drivers by tipping less or stiffing, passengers could instead exercise their discriminatory preferences by refusing to accept rides from black drivers. Unlike tipping less or stiffing, such a refusal would be costly for the passenger. Passengers choosing to forgo the first available cab does not seem to us very likely.

140. For example, the disparate impact cause of action was only expressly added to the text of Title VII in 1991. See 42 U.S.C. $\S 2000 \mathrm{e}-2(\mathrm{k})$ (2000); Nicole J. DeSario, Note, Reconceptualizing Meritocracy: The Decline of Disparate Impact Discrimination Law, 38 HARV. C.R.-C.L. L. REV. 479, 484 (2003). 
types of disparate treatment so that a subset of passengers have the opportunity to chisel on paying for their service. The availability of alternative, affordable public transportation would also seem a relevant consideration. $^{141}$

The second countervailing effect concerns service incentives. Requiring "Tip Included" decals might reduce cab drivers' incentives to provide highquality service. While the service theory is certainly coherent, ${ }^{142}$ its empirical plausibility is less certain. Researchers have found that patrons' perception of service accounts for less than $2 \%$ of the variability in restaurant tipping percentages. ${ }^{143}$ They have also discovered that tipping is not significantly related to servers' or third parties' evaluations of the service. ${ }^{144}$ However, most of these studies suffer from the problem of restricted range; the potential for a tip (or the threat of being stiffed) may induce servers to provide essentially uniform, excellent service. Finding a weak correlation in such circumstances says almost nothing about how much the quality of service might decline if discretionary tipping were eliminated.

Other countries without tipping traditions, or without traditions of tipping nearly as significant amounts, seem to do just fine without granting so much payment discretion. ${ }^{145}$ Indeed, the earlier discussion on the racial antecedents of U.S. tipping norms raises the possibility that the American practice may be more a vestigial attribute of racial subordination and less a way of giving servers appropriate incentives.

141. Examining how normal, periodic increases in fares impact taxicab ridership could provide some basis for estimating the potential negative effects of our proposed $15 \%$ fare hike. So too, policymakers would be wise to consider how switches to service compris regimes have actually worked in practice.

142. However, with regard to nonrepeat customers, there remains the question of why a server would work harder, knowing that the one-off customer has no economic rationale to tip.

143. Lynn \& McCall, supra note 88 , at 211.

144. Id. at 205; see also Azar, supra note 10, at 10 ("When asked about it hypothetically, [people] therefore indicate a large sensitivity of tips to service quality. When faced with an actual tipping situation, however, the social pressure and the embarrassment that one feels when he tips poorly bring people to tip for poor service more than they thought they would tip when asked about it hypothetically.").

145. Information on international tipping norms can be found at QuinWell.com, International Rules of Tipping, http://www.quinwell.com/vaca/tipping.html (last visited Apr. 30, 2005). See also To-Do Travel Servs., Tipping on Travel, http://www.todotravel.com/English/tips/items/ money/t-mon3.htm (last visited Apr. 30, 2005) (noting that no tip is expected in "Australia and New Zealand (except for top restaurants), Scandinavia, Singapore, mainland China, Japan, South Pacific islands, and in Zambian hotels"). 


\section{CONCLUSION}

In this preliminary study (of just one thousand fares in a single city), we have shown that discretionary tipping facilitated prejudice in two different ways: (1) It allowed customers to discriminate against minority drivers, and (2) it possibly gave cab drivers a revenue-based incentive to refuse to pick up minority passengers. Changing to service compris regulation would likely mute both types of discrimination, although such a change would presumably discourage some poorer passengers from taking taxis and could reduce the quality of taxi service provided.

Of course, it is always important to question whether the findings of a small single-city study are representative of a larger phenomenon. To do this, we looked at the 2000 Census Integrated Public Use Microdata Series (which includes a more detailed survey of $5 \%$ of the population). While we found that black drivers in New Haven earn 7\% less per fare than white drivers, the reported hourly income of African-American taxi and limousine drivers in the national data was not statistically different from white drivers. The Census variables do not, however, distinguish between taxicab drivers and chauffeurs or separate out tipping from total income. We also found no evidence that African Americans substitute other jobs where consumer discretion might be a less important determinant of their compensation. For the nation as a whole, $18.4 \%$ of taxi drivers and chauffeurs were black. This is about a half of a standard deviation above the mean black percentage $(15.2 \%)$ for approximately thirty comparably skilled job categories.

While there are some important qualifications to our results (particularly with regard to censoring), ${ }^{146}$ this Essay provides an initial test of consumer-side discrimination. It also provides the first quantitative estimates of rational and irrational statistical discrimination. It is our belief that exposing the dual racial determinants of tipping suggests more generally that consumer discretion in retail transactions may give rise to unexpected civil rights concerns.

146. See supra Part V. Among other things, future researchers in this area would do well to consider randomizing the selection of participating drivers, more closely monitoring the drivers to avoid omitted data, and obtaining better controls for driver quality and passenger wealth (perhaps by surveying passengers directly). 


\section{APPENDIX}

This Appendix corrects for the deficiencies of the bivariate analysis in Sections III.A to III.C by offering a series of regressions testing whether the foregoing racial effects persist in a more nuanced analysis. Table 13 reports the result of four nested regressions that relate the tipping percentage to passenger and driver race as well as an increasing number of nonracial right-hand-side variables.

The first regression specification (reported in the first column) simply regresses the tipping percentage on passenger- and driver-race indicator variables. Because the white-driver and white-passenger variables are omitted, the constant term $(25.2 \%)$ equals the predicted tipping percentage for a white passenger tipping a white driver. The coefficients on the remaining variables represent the incremental difference for the specified driver or passenger racial type. For example, the first specification suggests that black-driver tips would be 6.7 percentage points lower than the tips given to a white driver (and the bold and underlined font indicates that this shortfall is statistically significant at the $1 \%$ level). ${ }^{147}$

The results of the first specification are consistent with the preceding analysis. The negative coefficients on the driver variables indicate that customers tip a lower percentage to minority drivers than to white drivers, and the negative coefficients on the passenger variables indicate that minority customers tip a lower percentage than white customers. For example, the regression suggests that black passengers tip 11.7 percentage points less than white passengers. Moreover, the regression lets us see for the first time that both types of racial disparity are statistically significant.

But the first specification still does not control for a host of nonracial factors that might be influencing the tipping percentage. Regression specifications 2 through 4 add successively more right-hand-side control variables to test whether the racial effects uncovered in the previous tables (and in specification 1) are merely the byproduct of what econometricians call "omitted variable" bias. Regression 2 adds twenty-six variables related

147. Because virtually all of our observations on the tipping percentage are positive, we also ran the regressions in Table 13 using a Tobit analysis that controls for censored data. The coefficients on minority-passenger and minority-driver variables were larger and more statistically significant using this procedure.

To ensure that the core results were not driven by outlier tips, we also reran the most controlled regression after imposing filters on the data that dropped observations with tipping percentages of more than $200 \%, 150 \%$, and so on (even checking the results when censoring tipping percentages larger than $25 \%$ ). The racial effects remained highly significant in every case, and the magnitude of the effects did not vary strongly for filters preserving tipping percentages greater than $50 \%$ of the fare. 
to nonracial demographic characteristics of passenger and driver (such as age and gender) and to characteristics of the ride itself. Regression 3 then adds four more variables related to the crime rate (measured by number of 911 calls per resident) found in the pickup or drop-off neighborhoods. Finally, specification 4 adds individual indicator controls for forty-eight pickup and drop-off neighborhoods. ${ }^{148}$

Regressions 2 through 4 also employ a "random effects" estimation method. In this context, a random effects model tries to take into account that different drivers may have idiosyncratic propensities to be tipped a particular percentage. Imagine, for example, that some random process makes some people better or worse drivers (and hence more or less likely to receive a good tip). A random effects model simultaneously estimates (1) the size of these individual-driver random effects and (2) whether (after controlling for the individual-driver random effects) there are still statistically significant driver-race effects. ${ }^{149}$

The variance test reported for these regressions shows that estimated variance of the individual-driver random effects is not statistically different from 0 . This suggests that the individual-driver effects are not dominant in this data set. The real action in the data is between races and not idiosyncratic differences within each race. ${ }^{150}$

After controlling for random driver effects and a host of time, manner, and place effects, these specifications suggest that the customer discrimination result is quite robust. Adding additional variables to the regression does not materially impact the size or statistical significance of the driver-race variables. For the most complete regression (specification 4), we find that black drivers are tipped 9.1 percentage points less than white drivers (and that this result is statistically significant at the $1 \%$ level). This regression predicts that a black driver would be tipped $43.6 \%$ less than a similarly situated white driver ${ }^{151}$ and that this tipping shortfall causes the overall revenue per fare for black drivers to be $7.0 \%$ less than that of white

148. There are sixty-one neighborhood dummies, but many of these were dropped as a result of multicollinearity. To save space, neighborhood dummy effects are not reported. We also ran these regressions allowing Stata to choose which variables to drop. This produced essentially the same results.

149. The Hausmann tests that are reported for these regressions cannot reject the hypothesis that the random effects regression is appropriate (relative to a fixed effects regression).

150. For more discussion of this issue, see supra Part IV.

151. The tipping-percentage shortfall of $9.0 \%$ divided by the predicted white-driver tip percentage (evaluated at the means of the non-driver-race variables) of $20.9 \%$ equals $43.6 \%$. 
drivers. ${ }^{152}$ This passenger discrimination imposes the economic equivalent of a $7 \%$ tax on the income of black cab drivers. ${ }^{153}$

The finding that minorities tip systematically less, in contrast, is not as robust to the inclusion of additional right-hand-side controls. The size of the coefficients becomes smaller as additional controls are added, and the Hispanic disparity becomes less statistically significant. For the most complete regression (specification 4), the size of the black-passenger effect is diminished to a 9-percentage-point shortfall (from an 11.7-percentagepoint one in specification 1).

That is still a substantial disparity, but there is a potentially serious omitted-variable problem. Even our most complete specification contains only weak independent variables regarding the socioeconomic class of the passenger: dress and pickup and drop-off locations. With better measures of socioeconomic status, the apparent propensity of minorities to tip less might be a mere artifact of the likely propensity of poorer people to tip less.

The regressions also suggest that customers discriminate against older drivers. Specification 4 shows that a driver whose age is one standard deviation (about eight years) above the mean driver age (about forty) should expect to receive tips that are 4.5 percentage points less than average. This disparity is statistically significant at the $10 \%$ level $(p<.1) .^{154}$

With respect to norms of tipping more generally, the nonracial controls provide a potpourri of interesting results. In contrast to driver age, we learn that older passengers tip a systematically higher percentage. In our data, for example, a passenger whose age was one standard deviation above the mean passenger age was predicted in regression 4 to tip 3.4 percentage points more.

We also learn in specification 4 that the tipping percentage is statistically higher during inclement weather (an additional 13.6 percentage points), for acquaintances (10 percentage points), and for lower fares (10.3 percentage points). ${ }^{155}$ In contrast, we found no passenger-gender effects.

152. The revenue shortfall of $\$ 0.76$ divided by the predicted white-driver revenue (evaluated at the means of the non-driver-race variables) of $\$ 10.82$ equals $7.0 \%$.

153. In simple economic models, the lower revenues available to minority drivers would tend to cause minorities to substitute away from driving cabs so that they would not have to pay this discrimination tax. But our conversations with both minority and nonminority drivers suggest that the drivers are not well informed about the discrepancies in customers' willingness to tip minority drivers. And even if minority drivers learned of their ill treatment, they may also face restricted opportunities in finding and being compensated for other forms of employment.

154. It is important to note that the model also includes a variable for weeks of driver experience, which yielded a positive but not statistically significant coefficient. Thus, the results suggest that although there may be a slight advantage to experience (all else being equal), the more significant effect is that older drivers at a given experience level receive lower tips.

155. The regression suggests that the tipping percentage increases with amount due squared. But we found that the squared term only began to dominate the linear term for fare amounts due that were out of sample (approximately \$186). 
Men and women seem to tip roughly the same percentage in all of our specifications.

TABLE 13. REGRESSIONS WITH

TIPPING PERCENTAGE as DEPENDENT VARIABLE

\begin{tabular}{|l|l|l|c|c|c|c|}
\hline \multicolumn{2}{|l|}{} & 1 & 2 & 3 & $4^{156}$ \\
\hline Constant $^{157}$ & & & $\underline{0.252}$ & $\underline{0.379}$ & 0.289 & 0.410 \\
\hline
\end{tabular}

\begin{tabular}{|r|l|l|l|l|l|l||}
\hline Racial effects: & & & & & & \\
\hline Driver black & & & $\underline{-0.067}$ & $\underline{-0.095}$ & $\underline{-0.092}$ & $\underline{-0.091}$ \\
\hline Driver other & & & $-\mathbf{- 0 . 0 6 7}$ & $\underline{-0.166}$ & $\underline{-0.158}$ & $\underline{-0.134}$ \\
\hline Passenger black & & & $\underline{-0.117}$ & $\underline{-0.093}$ & $\underline{-0.090}$ & $\underline{-0.090}$ \\
\hline Passenger Hispanic & & & $\underline{-0.093}$ & $\mathbf{- 0 . 0 6 1}$ & $\mathbf{- 0 . 0 6 5}$ & -0.042 \\
\hline Passenger Asian & & & $\underline{-0.053}$ & -0.044 & -0.048 & -0.047 \\
\hline Passenger other & & & -0.107 & -0.058 & -0.051 & -0.022 \\
\hline
\end{tabular}

\begin{tabular}{|c|c|c|c|c|c|}
\hline Other variables: ${ }^{158}$ & Mean & $\begin{array}{l}\text { Standard } \\
\text { deviation }\end{array}$ & & & \\
\hline Passenger female & & & -0.004 & -0.004 & -0.01 \\
\hline Passenger age & 32.77 & 13.45 & $\underline{0.041}$ & $\underline{0.042}$ & $\underline{0.034}$ \\
\hline Driver age & 39.79 & 7.95 & -0.035 & $\underline{-0.04}$ & $\underline{-0.045}$ \\
\hline Below-average dress & & & -0.034 & -0.035 & -0.020 \\
\hline Above-average dress & & & 0.032 & 0.033 & 0.036 \\
\hline Weeks driving cab & & & 0 & 0 & 0.001 \\
\hline Survey experience ${ }^{159}$ & & & -0.015 & -0.009 & -0.016 \\
\hline Conversation $(1=$ yes $)$ & & & 0.029 & 0.023 & 0.019 \\
\hline Repeat passenger $(1=$ yes $)$ & & & 0.039 & 0.047 & 0.052 \\
\hline Acquaintance $(1=$ yes $)$ & & & $\underline{0.110}$ & $\underline{0.112}$ & $\underline{0.100}$ \\
\hline $\begin{array}{r}\text { Multiple passengers } \\
(1=\text { yes })\end{array}$ & & & $\underline{0.038}$ & $\underline{0.037}$ & 0.045 \\
\hline
\end{tabular}

156. Neighborhood dummies were included in this regression-the coefficients are not reported.

157. The omitted categories for the indicator variables are Driver White, Passenger White, Average Dress, Pickup Neighborhood with Average 911 Calls, and Drop-off Neighborhood with Average 911 Calls. To avoid losing observations and to keep the omitted category pure, indicator variables equal to 1 for missing data were also included but are not reported.

158. For continuous variables, the effects of a one-standard-deviation change are reported.

159. Survey Experience is defined on a scale of 1 to 3, depending on whether the driver was filling out his first, second, or third set of surveys. 


\begin{tabular}{|c|c|c|c|c|c|}
\hline $\begin{array}{c}\text { Dispatched pickup } \\
(1 \text { - yes) }\end{array}$ & & & 0.010 & 0.017 & 0.000 \\
\hline Amount die & 9.26 & 11.51 & $\underline{-0.108}$ & -0.105 & $\underline{-0.103}$ \\
\hline Amount due squared & 218.03 & 1123.09 & $\underline{0.062}$ & $\underline{0.062}$ & 0.054 \\
\hline Fare $\$ 0.25$ & & & 0.037 & 0.036 & 0.057 \\
\hline fare 8050 & & & 0.051 & 0.053 & 0.052 \\
\hline Tare 80.75 & & & 0.001 & 0.000 & 0.017 \\
\hline Cash $(1$ - yes) & & & 0.002 & 0.007 & 0.002 \\
\hline Travel time & 9.94 & 11.89 & -0.026 & -0.023 & -0.01 \\
\hline Travel distance & 4.59 & 7.73 & 0.05 & 0.045 & 0.033 \\
\hline $\begin{array}{l}\text { Average speed } \\
\text { (travel tine/travel distance) }\end{array}$ & 0.45 & 0.34 & -0.02 & -0.015 & -0.007 \\
\hline $\begin{array}{l}\text { Night (between } \\
7 \mathrm{pm} \text { ard } 7 \text { a m } 1 \text { - yes) }\end{array}$ & & & 0.017 & 0.025 & 0.025 \\
\hline $\begin{array}{l}\text { Late night (between } \\
11 \mathrm{~b} \text {. and } 5 \mathrm{am}, 1 \text { - yes) }\end{array}$ & & & 0.012 & 0.010 & -0.025 \\
\hline Temperature & 52.25 & 10.38 & -0.012 & -0.008 & -0.005 \\
\hline Rainssiow $(1-$ yes) & & & $\underline{0.206}$ & $\underline{0.196}$ & 0.136 \\
\hline I uggage $(1=$ yes) & & & 0.020 & 0.017 & 0.008 \\
\hline $\begin{array}{l}\text { Plakrp reighborhood with } \\
\text { below-average } 911 \text { ealls }\end{array}$ & & & & -0.012 & -0.074 \\
\hline $\begin{array}{l}\text { Pickup neighborhood with } \\
\text { above-average } 911 \text { calls }\end{array}$ & & & & $\underline{0.047}$ & 0.025 \\
\hline $\begin{array}{l}\text { Drop-off neighibothood with } \\
\text { below-average } 911 \text { calls }\end{array}$ & & & & 0.044 & 0.167 \\
\hline $\begin{array}{l}\text { Drop off ne'ghborhood with } \\
\text { above-average } 911 \text { calls }\end{array}$ & & & & 0.026 & -0.019 \\
\hline Tran pickup & & & & & -0.010 \\
\hline Trall drop off & & & & & -0.021 \\
\hline
\end{tabular}

\begin{tabular}{|c|c|c|c|c|}
\hline Niniber of observations & 1059 & 841 & 841 & 841 \\
\hline$R^{2}$ & 0.0605 & 0.196 & 0.203 & 0.298 \\
\hline Randon effects & no & yes & yes & yes \\
\hline Tlausmann test & & not sig. & not sig. & not sig. \\
\hline Variance test & & not sig. & not sig. & not sig. \\
\hline
\end{tabular}

Note: Underlined coefficients are significant at the $10 \%$ level, coefficients in bold are significant at the $5 \%$ level, and coefficients underlined and in bold are significant at the $1 \%$ level.

160. 911 Calls categories are based on total year-2000 911 calls divided by neighborhood population, with extrapolations to missing data/suburbs.

161. Observations fell out of models for two reasons: (1) incomplete driver surveys and (2) a midstudy change in survey design replacing type of building with neighborhood for the pickup and drop-off information. 
A variant of the foregoing regression specifications can also be used to test whether our earlier finding-that minority passengers seem to participate in the discrimination against minority cab drivers-is statistically significant and robust to inclusion of other right-hand-side controls. The previous regressions do not allow for such a test because the passenger- and driver-race effects were forced by the specification to enter independently. But it is possible in a less constrained specification to have the regressions estimate effects for all fifteen of the possible driverrace/passenger-race permutations. By including these interaction effects it becomes possible to test, for example, whether black passengers tend to tip black drivers statistically less than white drivers.

Table 14 reports the tipping-percentage shortfalls for minority drivers (relative to white drivers) from particular passenger races in regression specifications that are otherwise identical to specifications 1 through 4 in Table 13. For example, we see in specification 2 that white passengers tip black drivers 10.4 percentage points less than white drivers. The blackdriver shortfall is large and statistically significant in all of the specifications.

Again, there is some evidence that minorities discriminate against black drivers, but the differences are less significant than in the case of white passengers. The reported black-passenger/black-driver disparities are all negative, indicating an estimated shortfall for black drivers. For the most controlled specification, however, the black-driver shortfalls are only significant at the $10 \%$ level. Many of the other driver-race/passenger-race permutations were statistically not different from either 0 or the analogous white-passenger coefficient. However, we may be simply running into a small-numbers (or what econometricians sometimes call a "degrees of freedom") problem. When you ask a regression to estimate fifteen separate driver-race/passenger-race effects as well as nearly 100 other right-hand control variable effects, it can become increasingly difficult to identify statistically significant effects. 


\section{TABLE 14. TESTS OF CONSUMER/PASSENGER DISCRIMINATION AGAINST DIFFERENT DRIVER RACE, BY PASSENGER RACE}

\begin{tabular}{|c|c|c|c|c|c|}
\hline \multirow[b]{2}{*}{ Passenger trace } & \multirow[b]{2}{*}{ briver race } & \multicolumn{4}{|c|}{$\begin{array}{l}\text { Mnomity-driver disparity (relative to white drivers) } \\
\text { Difrerence in driver effects }\end{array}$} \\
\hline & & 1 & 2 & 3. & 4 \\
\hline \multirow{2}{*}{ White } & Black & -0.088 & -0.104 & $\underline{-0.1}$ & -0.101 \\
\hline & Other & -0.135 & $\underline{-0.212}$ & -0.208 & -0.166 \\
\hline \multirow{2}{*}{ Black } & Black & -0.036 & -0.079 & -0.075 & -0.064 \\
\hline & Other & 0.021 & -0.104 & -0.095 & -0.071 \\
\hline \multirow{2}{*}{ Mispanic } & Black & -0.104 & -0.092 & -0.093 & -0.112 \\
\hline & Other & -0.062 & -0.161 & -0.152 & -0.149 \\
\hline \multirow{2}{*}{ Astinan } & Black & 0.020 & -0.062 & -0.065 & -0.055 \\
\hline & Other & -0.038 & -0.186 & -0.176 & -0.158 \\
\hline \multirow{2}{*}{ Otter. } & Black & -0.038 & -0.037 & -0.049 & -0.094 \\
\hline & Other & -0.130 & -0.058 & -0.078 & -0.070 \\
\hline
\end{tabular}

Note: Underlined coefficients are significant at the $10 \%$ level, coefficients in bold are significant at the $5 \%$ level, and coefficients underlined and in bold are significant at the $1 \%$ level.

This evidence that black passengers discriminate against black drivers may at first seem to contradict the "for us, by us" spirit that is often promoted in communities of color. ${ }^{163}$ But as a conceptual matter, while FUBU preferences will lead to a greater tendency toward same-race contracting, they do not clearly suggest whether a FUBU price would be higher or lower. With regard to the net price, FUBUism is a two-way street that could lead to either higher or lower black-on-black tips. After all, service providers have been known to refuse tips from passengers of the same nationality. ${ }^{164}$ This dual nature may be partially reflected in a recent survey conducted by American Demographics. ${ }^{165}$ The survey found that African Americans were almost four times more likely than whites to say

162. These effects are based on regressions of the same form as $1,2,3$, and 4 where the passenger- and driver-race variables are replaced with interacted variables.

163. See supra note 4.

164. Coauthor Zakariya (who is Arab American) reports encountering retailers who offered him lower prices because they shared the same ethnicity. On the other hand, coauthor Ayres (who is white) reports encountering cab drivers outside the United States who refused tips because they had differing ethnicity (i.e., because Ayres was a "guest" in their country).

165. Pamela Paul, The Tricky Topic of Tipping, AM. DEMOGRAPHICS, May 2001, at 10, $10-11$. 
that they would tip a minority server more than a white server for good service (9.0\% versus 2.3\%). But African Americans were also almost four times more likely to say that they would tip a minority server less $(4.1 \%$ versus $1.1 \%){ }^{166}$

To further analyze stiffing behavior, we regressed the stiffing indicator against the same set of independent variables in the tipping-percentage specifications. Table 15 reports the results of these regressions, now relating the probability of stiffing to passenger and driver race and the nested set of nonracial right-hand-side variables.

Because stiffing is a dummy variable, we ran the analogous stiffing regressions using probit models, so that the output in Table 15 indicates the change in the likelihood of a stiff on the basis of a discrete $0-1$ change in the dummy variables or a one-standard-deviation change in the continuous variables. Thus, in the first specification, the black-driver coefficient of 10.7 indicates that a black driver is about 11 percentage points more likely to be stiffed than a white driver.

Once again, the results of all specifications are quite consistent with our initial tabulations: Minority passengers are more likely to stiff, and minority drivers are more likely to be stiffed. For example, in all specifications, a black passenger is significantly more likely to stiff than a white passenger, though with decreasing magnitude as we add more controls. In addition, we now see that the majority of these effects are highly significant $(p<.01)$.

Again, the consumer discrimination effects, now in terms of stiffing, remain robust to the addition of racial and nonracial controls. Although the second and third regressions yield black-driver effects that are significant only at the $10 \%$ level, the magnitude of the effects remains roughly in the area of 10 percentage points. The most controlled specification is significant at the $1 \%$ level, indicating that black drivers are almost 10 percentage points more likely to be stiffed than white drivers (while, according to the same specification, "other minority" drivers are almost 24 percentage points more likely to be stiffed).

As in the case of the tipping regressions, the passenger effects tend to diminish with the addition of more controls. Comparing the first and fourth regressions, we see that the black-passenger effects diminish by more than 11 percentage points and that the Hispanic-passenger effects diminish by more than 15 percentage points - although the broad levels of significance remain the same. ${ }^{167}$

166. These percentages were generously provided by Michael Lynn, who obtained the full unpublished report (and the raw data) from TNS Intersearch.

167. However, it is again important to keep in mind that none of our specifications contain good controls for the socioeconomic class of the passenger, so effects that the stiffing regressions 
Not surprisingly, many of the nonracial controls that were significant in the tipping-percentage regressions remain significant in the stiffing regressions. ${ }^{168}$ Passenger and driver age, above-average dress, and acquaintance of driver with passenger yield largely significant effects with the same tendencies as in the tipping regressions. ${ }^{169}$ So, for example, in the fourth regression, we see that a passenger one standard deviation above the mean age is $5 \%$ less likely to stiff, while a driver one standard deviation above the mean age is $4.4 \%$ more likely to be stiffed. Again, this suggests that passengers may have engaged in discrimination against older cab drivers as well.

are attributing to race may in fact be more dependent on the wealth of the passenger. This fact and its implications for cab driver inferences are considered further supra Section V.C.

168. Note, however, that the fare dummies are all negative and highly significant. This indicates that passengers are more likely to stiff with integer fares than with any other type, perhaps in part because letting the driver "keep the change" is an option for noninteger fares. We discuss this further supra text accompanying notes 103-104. Also, somewhat surprisingly to our minds, a passenger paying cash is less likely to stiff. Some drivers may have neglected or refused to record a noncash tip.

169. Though rain and snow are not significant disincentives to stiffing in these regressions, the temperature effects show that passengers are about $2.3 \%$ less likely to stiff with every $10 \%$ drop in temperature, suggesting that cold or inclement weather does have some prohibitive effect on stiffing. Additionally, passengers are more likely to stiff at night under the cover of darkness (4.5\% more likely in the fourth regression, and significant at the $5 \%$ level). 
TABLE 15. REGRESSIONS WITH STIFFING AS DEPENDENT VARIABLE

\begin{tabular}{|c|c|c|c|c|}
\hline & 1 & 2 & 3 & $4^{170}$ \\
\hline \multicolumn{5}{|l|}{ Racial effects: ${ }^{17}$} \\
\hline Driver black & $\underline{0.107}$ & $\underline{0.10}$ & $\underline{0.096}$ & $\underline{0.098}$ \\
\hline Driver other & $\underline{0.223}$ & $\underline{0.194}$ & $\underline{0.176}$ & $\underline{0.239}$ \\
\hline Passenger black & $\underline{0.307}$ & $\underline{0.279}$ & $\underline{0.273}$ & $\underline{0.192}$ \\
\hline Passenger Hispanic & $\underline{0.286}$ & $\underline{0.198}$ & $\underline{0.205}$ & $\underline{0.131}$ \\
\hline Passenger Asian & 0.061 & 0.087 & 0.088 & $\underline{0.102}$ \\
\hline Passenger other & 0.306 & 0.188 & 0.180 & 0.181 \\
\hline
\end{tabular}

\begin{tabular}{|c|c|c|c|c|c|}
\hline Other variables: & Mean & $\begin{array}{l}\text { Standard } \\
\text { deviation } \\
\end{array}$ & & & \\
\hline Passenger female & & & 0.006 & 0.006 & 0.004 \\
\hline Passenger age & 32.77 & 13.45 & -0.032 & -0.035 & -0.050 \\
\hline Driver age & 39.78 & 7.95 & 0.017 & 0.018 & 0.044 \\
\hline Below-average dress & & & $\underline{0.069}$ & $\underline{0.069}$ & 0.062 \\
\hline Above-average dress & & & $\underline{-0.093}$ & -0.087 & $\underline{-0.065}$ \\
\hline Weeks driving cab & & & 0.001 & 0.001 & 0.000 \\
\hline Survey experience $\mathrm{e}^{\mathrm{ln2}}$ & & & 0.001 & -0.007 & -0.005 \\
\hline Conversation $(1=$ yes $)$ & & & -0.016 & -0.005 & 0.015 \\
\hline Repeat passenger $(1=$ yes $)$ & & & 0.013 & -0.003 & -0.014 \\
\hline Acquaintance $(1=$ yes $)$ & & & -0.068 & -0.067 & -0.035 \\
\hline $\begin{array}{r}\text { Multiple passengers } \\
(1=\text { yes })\end{array}$ & & & 0.013 & 0.013 & 0.008 \\
\hline Dispatched pickup $(1=$ yes $)$ & & & 0.017 & 0.006 & 0.01 \\
\hline Amount due & 9.26 & 11.506 & 0.034 & -0.051 & $\underline{-0.154}$ \\
\hline Amount due squared & 218.03 & 1123.09 & -0.134 & -0.010 & 0.088 \\
\hline Fare $\$ 0.25$ & & & $\underline{-0.138}$ & $\underline{-0.127}$ & $\underline{-0.104}$ \\
\hline
\end{tabular}

170. Neighborhood dummies were included in this regression the coefficients are not reported.

171. Coefficients reported here are the changes in the probability of stiffing resulting from infinitesimal changes in the continuous variables and discrete changes in the indicator variables from 0 to 1 . For continuous variabies, the effects of a one-standard-deviation change are reported. The omitted categories for the indicator variables are Driver White, Passenger White, Average Dress, Pickup Neighborhood with Average 911 Calls, and Drop-off Neighborhood with Average 911 Calls. To avoid losing observations and to keep the omitted category pure, indicator variables equal to 1 for missing data were also included but are not reported.

172. Survey Experience is defined on a scale of 1 to 3, depending on whether the driver was filling out his first, second, or third set of surveys. 


\begin{tabular}{|c|c|c|c|c|c|}
\hline Fare soso & & & -0.161 & -0.154 & $\underline{-0.133}$ \\
\hline Tare so. 75 & & & -0.185 & $\underline{-0.177}$ & -0.151 \\
\hline (cash 1 -yes) & & & $\underline{-0.360}$ & $\underline{-0.395}$ & -0.285 \\
\hline Travel time & 9.94 & 11.89 & 0.029 & 0.058 & 0.110 \\
\hline - Travel distance & 4.59 & 7.727 & -0.084 & -0.114 & -0.146 \\
\hline $\begin{array}{l}\text { Average speed (travel) } \\
\text { trmet travel distance) }\end{array}$ & 0.45 & 0.34 & 0.019 & 0.024 & 0.039 \\
\hline 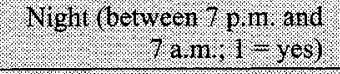 & & & $\underline{0.073}$ & 0.066 & 0.045 \\
\hline $\begin{array}{l}\text { Late night (between } 11 \mathrm{pm} \\
\text { and } 5 \text { a m. } 1 \text { - yes) }\end{array}$ & & & -0.047 & -0.034 & 0.008 \\
\hline Temperature & 52.25 & 10.38 & 0.030 & $\underline{0.029}$ & $\underline{0.023}$ \\
\hline Rain snow $(1=y e s)$ & & & -0.030 & -0.021 & 0.028 \\
\hline Luggage $(1-y e s)$ & & & -0.104 & $\underline{-0.099}$ & $\underline{-0.077}$ \\
\hline $\begin{array}{l}\text { Pickup neighborhood with } \\
\text { below-average } 911 \text { cals }\end{array}$ & & & & 0.500 & $\underline{\mathbf{0 . 8 9 0}}$ \\
\hline $\begin{array}{l}\text { Preklp neighlborhood with } \\
\text { above-average } 911 \text { calls }\end{array}$ & & & & -0.038 & $\underline{0.642}$ \\
\hline $\begin{array}{l}\text { Drop-eff neighborhood with } \\
\text { below-average } 911 \text { calls }\end{array}$ & & & & 0.059 & -0.062 \\
\hline $\begin{array}{l}\text { Drop off neighborthood with } \\
\text { above-average } 911 \text { calls }\end{array}$ & & & & -0.022 & 0.116 \\
\hline Train prekup & & & & & $\underline{0.105}$ \\
\hline Tran drop-ofl & & & & & 0.073 \\
\hline
\end{tabular}

\begin{tabular}{|l|c|c|c|c|}
\hline Number of observat ons ${ }^{14}$ & 1059 & 837 & 837 & 837 \\
\hline Pseudo $R^{2}$ & 0.119 & 0.313 & 0.332 & 0.416 \\
\hline
\end{tabular}

Note: Underlined coefficients are significant at the $10 \%$ level, coefficients in bold are significant at the $5 \%$ level, and coefficients underlined and in bold are significant at the $1 \%$ level.

All in all, the regression analysis suggests that there is strong evidence of customer discrimination against minority drivers measured by tipping and stiffing differences that persists and is statistically significant after controlling for a variety of nonracial factors. And there is some evidence that black and Hispanic passengers participate in this discrimination, although the estimates of minority-driver shortfalls in the most controlled regression are less significant.

173. 911 Calls categories are based on total year-2000 911 calls divided by neighborhood population, with extrapolations to missing data/suburbs.

174. Observations fell out of models for two reasons: (1) incomplete driver surveys and (2) a midstudy change in survey design replacing type of building with neighborhood for the pickup and drop-off information. 